\title{
Retórica simbólica en el espacio arquitectónico \\ Una mirada antropológica de la casa en la sobremodernidad
}

\author{
Eska Elena Solano-Meneses \\ Universidad Autónoma del Estado de México \\ Facultad de Arquitectura y Diseño
}

Solano-Meneses, E. E. (2018) Retórica simbólica en el

espacio arquitectónico. Una mirada antropológica de la casa en la sobremoderni-

dad. Revista de Arquitectura

(Bogotá), 20(2), 51-61. doi: http://dx.doi.org/10.14718/ RevArq.2018.20.2.1848

http://dx.doi.org/10.14718/RevArq.2018.20.2.1848

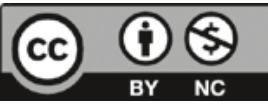

\author{
Arquitecta, Facultad de Arquitectura y Diseño, Universidad Autónoma del Estado de México (UAEMex) \\ (México). \\ Maestra en Educación, Tecnológico de Monterrey (México). \\ Doctora en Diseño, Universidad Autónoma del Estado de México (UAEMex) (México). \\ Docente en posgrado del Centro de Investigación de Arquitectura y Diseño (CIAD) \\ Docente, Licenciatura en la Facultad de Arquitectura y Diseño en UAEMex y en el Tecnológico de Mon- \\ terrey. \\ Investigadora de tiempo completo en la Licenciatura en Diseño y posgrado en la MADIC de la Universidad \\ Autónoma Metropolitana Unidad Cuajimalpa (México). \\ Profesora de posgrado (doctorado), División de Ciencias y Artes para el Diseño, Universidad Autónoma \\ Metropolitana, Xochimilco (México) \\ Colaboradora en el programa del Doctorado en Diseño, UAEMex. Miembro del SNI Nivel I. \\ Líneas de investigación: semiótica, hermenéutica, retórica, arquitectura, diseño y educación inclusiva. \\ (D) https://orcid.org/0000-0002-5974-I5 | \\ eskasolano@gmail.com
}

\section{Resumen}

Se analizan los aspectos simbólicos de la casa sobremoderna, mediante el uso metodológico de variables antrópicas. Se parte de la idea de la casa como espacio antropológico celular y como espacio mínimo en que el hombre se desarrolla, generalmente resuelto arquitectónicamente en términos de estética y función. Sin embargo, su enfoque antropológico no se ha atendido desde la arquitectura, antes bien, se ha limitado y transgredido, lo que ha provocado una crisis en los espacios habitados. La propuesta metodológica de enfoque etnográfico se sustenta en una dimensión antropológica de los espacios, a través de la inclusión de variables de diseño arquitectónico que surgen del análisis de la pirámide de Maslow. Se concluye que aspectos como autorrealización, seguridad y pertenencia, por mencionar algunos, resultan vulnerados con los planteamientos arquitectónicos actuales, situación que afecta el sentido simbólico de la casa sobremoderna.

Palabras clave: arquitectura, casa, espacio, etnografía, necesidades básicas.

Symbolic Rhetoric in the Architectural Space: An Anthropological View of the House in the Age of Supermodernity

\section{Abstract}

This research aims to analyze the symbolic aspects of the supermodern house, with a methodology that uses anthropic variables. It is based on the idea of the house as a cellular anthropological space, the minimum space in which human beings develop, generally determined architecturally in terms of aesthetics and function. Nevertheless, this anthropological approach has not been addressed from architecture; rather, it has been limited and infringed, causing a crisis in inhabited spaces. The methodological proposal of an ethnographic approach is based on the anthropological dimension of spaces, through the inclusion of architectural design variables that arise from the analysis of the Maslow pyramid. The paper concludes that aspects such as self-realization, security and belonging, among others, are violated under the current architectural approaches, a situation that affects the symbolic sense of the supermodern house.

Keywords: Architecture, house, space, ethnography, basic needs.

\section{Retórica simbólica no espaço arquitetônico. Um olhar antropológico da casa na sobremodernidade}

\section{Resumo}

São analisados os aspectos simbólicos da casa sobremoderna, a partir do uso metodológico de variáveis antrópicas. Parte-se da ideia da casa como espaço antropológico celular e como espaço mínimo em que o homem se desenvolve, geralmente solucionado arquitetonicamente em termos de estética e função. Porém, o seu enfoque antropológico não foi atendido a partir da arquitetura, senão que se limitou e transgrediu, o que tem provocado uma crise nos espaços habitados. A proposta metodológica de enfoque etnográfico é sustentada em uma dimensão antropológica dos espaços, através da inclusão de variáveis de design arquitetônico que surgem da análise da pirâmide de Maslow. Conclui-se que aspectos como autorrealização, segurança e pertencimento, para mencionar alguns, terminam vulnerados com as propostas arquitetônicas atuais, situação que afeta o sentido simbólico da casa sobremoderna.

Palavras-chave: arquitetura, casa, espaço, etnografia, necessidades básicas.
Evaluado: mayo $11 / 2018$

\section{Introducción}

Este artículo corresponde al proyecto de investigación denominado "Sustentabilidad social en los estudios urbanos y arquitectónicos", realizado en la Universidad Autónoma del Estado de México (UAEMEX).

Los resultados de esta investigación se centran en develar las condiciones en que las necesidades antrópicas se atienden en un espacio simbólico como la casa, desde un sentido antropológico profundo. La investigación se desarrolló en dos modelos de casa sobremoderna, ubicados en el Fraccionamiento Rincón del Álamo, localizado en el municipio de Almoloya de Juárez en el Valle de Toluca.

La casa, entendida genéricamente como aquel espacio destinado a la habitación humana, ha estado sujeta a un proceso de evolución que responde a las condiciones y el contexto cultural del cual subyace. Su concepto inicial atiende aspectos formales y funcionales heredados de las ideas de la modernidad, y desatiende aspectos simbólicos (antrópicos), como son las necesidades psicológicas y emocionales referidas en la pirámide de Maslow.

La sobremodernidad, por tanto, es la etapa de la posmodernidad que se caracteriza por legitimar, de manera reiterada, principios de la modernidad supuestamente ya superados, donde nuevamente hay un desapego con aspectos culturales y simbólicos.

Simbólico es el término utilizado por Clifford Geertz (1996) para acotar los aspectos socioculturales (identitarios) de un pueblo bajo un enfoque antropológico, y desasociarse de la idea de "cultura" como lo relacionado con el conocimiento propio de grupos "élites". 
La investigación pretende responder a la pregunta: ¿cuáles son las necesidades antrópicas que la casa debe satisfacer, independientemente de la forma y función?

La hipótesis de que se parte es que además de las necesidades estéticas y funcionales que una casa debe cubrir, es importante la satisfacción de necesidades de carácter más profundas como las simbólicas.

Se parte del antecedente de que las primeras manifestaciones de la arquitectura no fueron una respuesta primitiva para satisfacer necesidades fisiológicas y protegerse de las inclemencias del tiempo, sino que representan una significación más simbólica del espacio, centrándose más en una dimensión mística y religiosa que constructiva, como fue el caso de la arquitectura megalítica.

Posteriormente, propuestas teóricas desde Vitrubio hasta Palladio se centraron en la lógica del diseño arquitectónico apoyado en los emplazamientos, la buena ventilación, y el uso de materiales, así como técnicas de construcción para terminar por concebir a la casa como "objeto para habitar". Nunca manifestaron interés por aspectos simbólicos como seguridad y autorrealización.

Con la llegada de la arquitectura moderna, arquitectos como Frank Lloyd Wright, Mies van der Rohe y Le Corbusier ensalzan nuevos principios en los que domina la función acompañada por la forma; al tiempo que el racionalismo extiende la idea de estandarización de los espacios arquitectónicos hasta la masificación de la casa o residencia. Abanderada por la idea de una mejora de las condiciones de vida de sus habitantes, la arquitectura moderna propugna por ideas absolutas de una función universal, y olvida los aspectos simbólicos de la casa. Así se manifiesta en la propuesta le corbusiana de La Máquina de habitar al afirmar que es "una máquina destinada a procurarnos una ayuda eficaz para la rapidez y exactitud en el trabajo, una máquina diligente y atenta para satisfacer las exigencias del cuerpo" (Le Corbusier, 1978, p. 24).

Con la sobremodernidad, la preocupación de los aspectos simbólicos en el diseño de espacios para habitar se reconsidera, como respuesta a los espacios sobremodernos carentes de identidad. Desde los conceptos urbanos con Jane Jacobs (2011) y Aldo Rossi (1982) se defiende la necesaria inclusión de espacios de convivencia no estrictamente funcionales, así como la transformación de la idea de un espacio "definido por su función" en espacios indeterminados, transformables, susceptibles de alojar simultáneamente actividades diversas (Oliveras, Montaner, De Sola Morales y Ramón, 2000).
La nueva perspectiva desde una visión antropológica, asocia el concepto de casa con los arquetipos de Jung (2009), relacionados con lo simbólico por su cercanía con lo mítico y lo cultural (Coppola, 1997) y se afirma que las casas modernas "no recogen, la mayoría de las veces, las instancias arraigadas [...] recogen con mayor frecuencia necesidades de consumo más que las exigencias profundas y subconscientes del hombre" (p. 167). El concepto de arraigo, entendido como una recurrente tendencia a practicar algunas costumbres -ritos- que son consideradas como propias de la cultura de la cual proviene, contextualiza la importancia de lo simbólico en lo señalado por Coppola Pignatelli (1997).

Paradójicamente, a pesar de que el estado del arte señala la necesidad de inclusión de los aspectos simbólicos del hombre en el concepto de casa, la sobremodernidad retorna a las costumbres modernas, determinadas por el liberalismo económico de concebir los espacios de habitar como un producto que debe cumplir cuestiones de índole primordialmente económica, y después funcional y estética, lo que diluye los principios simbólicos de la casa.

\section{La casa como lugar}

La falta de significado del entorno arquitectónico se establece en los "no lugares" de Marc Augé, quien diferencia lugar y espacio, y señala que el lugar es el área que "ha adquirido significado a partir de las actividades humanas que se dan en ese sitio" (2002, p. 32), mientras el espacio carece de este nivel de identidad. Con ello, la casa ha de ser lugar y no espacio o no lugar.

Esta indiferencia contextual, señalada por Augé (2002) como No lugar, conlleva procesos antropológicos que los espacios carentes de significados generan, porque nadie siente ningún apego por él, consecuencia lógica de las características de la sobremodernidad o supermodernidad (Ibelings, 1998). Para Baudrillard (1988), el lugar ha sido sustituido por la desunión, el desencuentro y el extravío. La casa en su simbolismo esencial está en crisis, puesto que se le han eliminado las características de espacios identitarios, relacionales e históricos para ser sustituidos por cuestiones económicas y funcionales. El hombre y sus relaciones con sus semejantes no tienen cabida, con la soledad y el aislamiento consecuente de sus habitantes (Augé, 2002).

El hombre se concibe a sí mismo como inmerso en un espacio, lo que concede sentido y simbolización a su existencia (Morales, 1999), y deja clara la importancia del ser humano con el espacio (lugar). Narváez Tijerina (2004) agrega que un espacio simbólico ubica al hombre en un imaginario urbano, ya que los habitantes se autoconciben a través del establecimiento de relaciones 
espaciales cuyas representaciones les permiten una significación de su ser, tanto en la dimensión individual como colectiva.

Hoy en día, la falta de estos símbolos niega la naturaleza del hombre y conduce irremediablemente a una sociedad hacia el caos, a una falta de identidad y a una pérdida de sentido de pertenencia y de comunidad, que desata problemas sociales de toda índole.

Para Morales (1999), la identidad o pertenencia consiste en la conversión del espacio genérico (la vastedad) en espacio con connotación de lugar que da sentido a su existencia: "El hombre debe crear un orden arquitectónico para establecerse y entender el mundo. De ahí que la consideración aclaradora y situante nunca puede omitirse en las labores arquitectónicas" (Morales, 1999, p. 244), conceptos en los que Muntañola (1996) apoya la teoría de la topogénesis. Para él, el lugar es el espacio habitado, es el escenario del hombre, resume tiempo y espacio, y se construye con la existencia de un sujeto y su historia (otros). De ahí que la topogénesis sea el estudio de la construcción de lugares para vivir; de esta manera, el arquitecto se convierte en un generador de lugares. El lugar permite al sujeto navegar por la historia y permite a la historia situar al sujeto (Muntañola, 2009).

La función histórica y social de la arquitectura ha sido la creación necesaria de un espacio humanizado, hecho a imagen y semejanza del hombre para que este sobreviva. Un espacio que el hombre pueda habitar, su lugar.

El concepto de lugar de la casa se define tanto por las funciones como por la acción de los individuos que allí moran, y estos elementos "determinan los patrones de vida en la red social, simbólica y de creación, y son la base de la identidad" (De Hoyos, 2010, p. 213) de quien ahí vive.

\section{Metodología}

\section{Propuesta de fundamentos simbólicos en la casa sobremoderna}

Este trabajo propone una metodología etnográfica de análisis con enfoque cualitativo de la casa, cuya categorización se sustenta en variables simbólicas provenientes de la pirámide de Maslow, las cuales sirven de guía tanto para la investigación de campo como para analizar la información obtenida a través de instrumentos etnográficos como: historias de vida, entrevistas a profundidad, observación directa y shadowing. La interpretación de resultados se apoya en la heurística semiótica.

Los instrumentos del investigador son tanto la investigación documental como la de campo, dado que se pretende un acercamiento con los principales actores: las personas que habitan casas sobremodernas en el Fraccionamiento Rincón del Álamo, en la Villa de Almoloya de Juárez, en el Valle Metropolitano de Toluca, México.

El universo de estudio corresponde a las familias que habitan estas casas sobremodernas, por ser casos de estudio que cumplen con las características críticas de la arquitectura actual.

A partir de un enfoque cualitativo, se realizaron dos tipos de entrevista, la primera cuali-cuantitativa corresponde a un esquema de entrevista dirigida, la cual busca registrar datos objetivos que complementen la información obtenida con la entrevista no formal. Este tipo de entrevistas establecía la variable por medir y se proporcionaba al entrevistado una lista de conceptos alusivos, para que con ello describieran su percepción referente a concepto medido.

El segundo tipo, totalmente cualitativo, corresponde al establecimiento de una entrevista a profundidad, un diálogo libre en el que el actante-habitador se sienta en libertad de describir su experiencia como habitante de las casas del Fraccionamiento Rincón del Álamo, centrado básicamente en la narrativa de cómo es un día de su vida en su casa: cómo son sus experiencias, cómo se siente, qué espacios frecuenta, qué actividades realiza, con quién convive, etc., de manera que, bajo la perspectiva de la heurística semiótica, sea posible encontrar sustratos simbólicos en sus espacios, al tiempo que se conozca la situación con mayor profundidad.

Para la aplicación de la entrevista dirigida fueron entrevistadas 20 personas, ubicadas en diferentes rangos de edad, género, ocupación y que habitan las casas del fraccionamiento. De las personas entrevistadas un $40 \%$ resultó ser trabajador o empleado, un $40 \%$ es estudiante y un $20 \%$ se dedica al hogar.

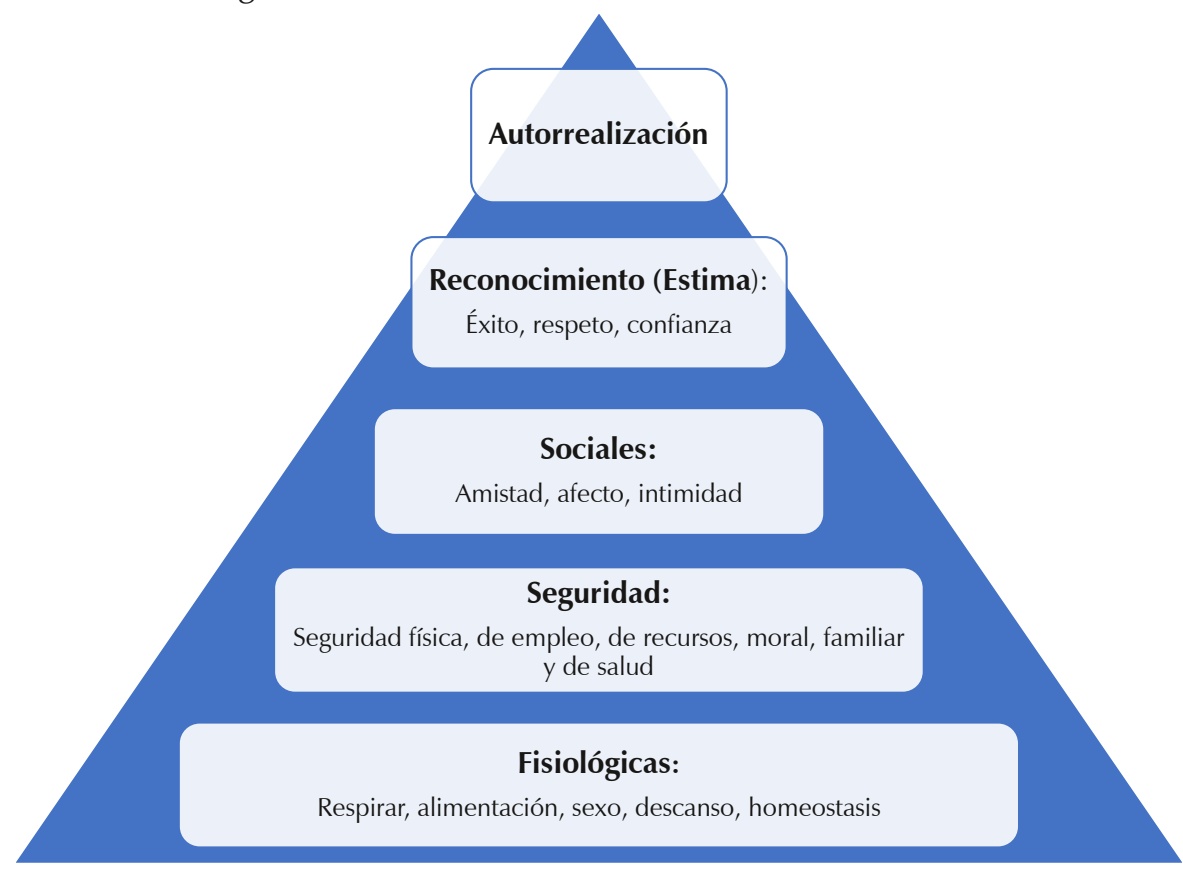

A Figura 1. Pirámide de Maslow, que señala los tipos de necesidades de un ser humano Fuente: elaboración propia a partir de Maslow (2009). 


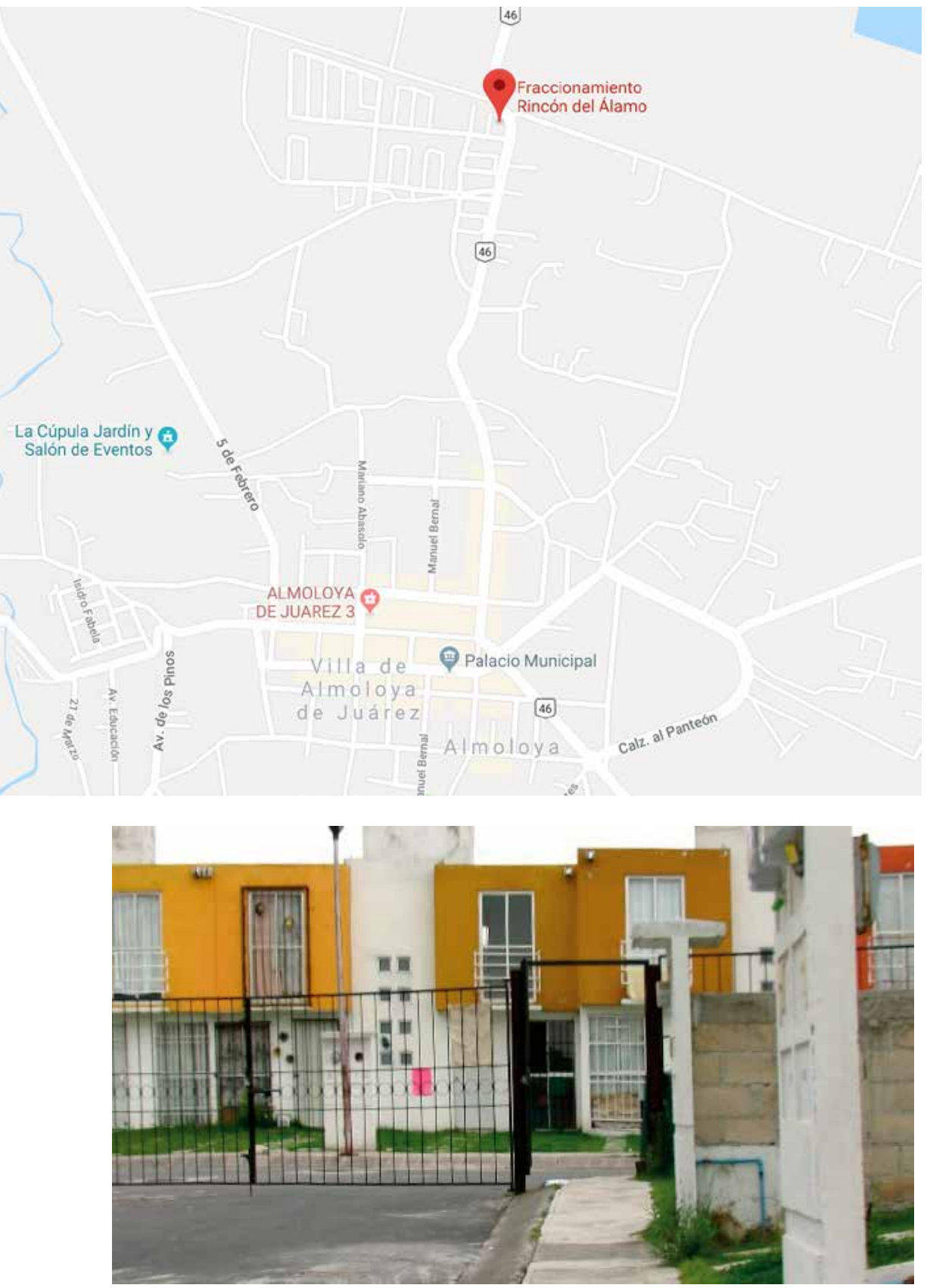

(A) Figura 2. Ubicación del fraccionamiento, al norte de Almoloya de Juárez

Fuente: Goolgle maps, 2018

\section{(A) Figura 3}

Fraccionamiento Rincón de Álamo

Fuente: elaboración propia, 2015
Las variables para la categorización del análisis simbólico surgen de la pirámide de Maslow (2009), la cual es una representación gráfica de la teoría de motivación propuesta por Abraham Maslow que pretende explicar las necesidades humanas (Figura 1). En la base de la pirámide aparecen las necesidades fisiológicas, seguidas de las necesidades de seguridad, sociales, de reconocimiento y autorrealización.

Cada una de estas necesidades tiene implicaciones en el diseño arquitectónico.

Necesidades básicas o fisiológicas: son las relacionadas con la supervivencia del individuo -respirar, alimentarse, hidratarse, vestirse, sexo, etc.-.

Necesidades de seguridad: se refieren a la necesidad de tener una situación de orden y seguridad en la vida. Estas pueden ser: seguridad física (salud), económica (ingresos), necesidad de vivienda, etc.

Necesidades sociales: implican el sentimiento de pertenencia a un grupo social, familia, amigos, pareja, compañeros del trabajo, etc.
Necesidades de estima o reconocimiento: tienen que ver con la confianza, la independencia personal, la reputación o las metas financieras.

Necesidades de autorrealización: son las más altas, estarán cubiertas si las demás necesidades han sido suficientemente alcanzadas. Es la sensación de haber llegado al éxito personal (Maslow, 2009).

De las necesidades detectadas por Maslow se desprende la presente propuesta, que pretende analizar la manera en que el espacio arquitectónico puede atender cada una de las dimensiones citadas por el autor.

Estas variables son:

1. Sentido de satisfacción personal asociado al espacio o lugar.

2. Sentido de afiliación.

3. Sentido de protección y defensa.

4. Sentido de reconocimiento.

5. Sentido de pertenencia y arraigo con el entorno.

6. Sentido de proximidad con el otro.

7. Sentido de satisfacción de aspectos físico-mentales.

8. Sentido de asociación del espacio con su uso psicológico y social.

Los estudios de Maslow ligados a las necesidades del hombre coinciden también con posturas de teóricos del diseño como Papanek, quien afirma: "'cuando decimos que las necesidades básicas de la gente están resueltas' no hacemos más que plantear una opinión estrecha y provinciana. [...] las verdaderas necesidades de las amplias masas del pueblo siguen sin solucionarse" (2014, p. 181), refiriéndose con ello a superar aspectos estéticos y funcionales en el diseño, para atender las simbólicas.

\section{Caso de estudio: casas del conjunto} habitacional Rincón del Alamo

Desarrollado en la zona poniente del Valle Metropolitano de Toluca, las casas del Fraccionamiento Rincón del Álamo se localizan aproximadamente a $1,5 \mathrm{~km}$ al norte del poblado de Almoloya de Juárez (Figura 2). Es un fraccionamiento compuesto por 1013 casas (Figura 3).

El fraccionamiento ofrece dos modelos de casas (Figura 4):

Modelo Malva, tiene una superficie de terreno de $60 \mathrm{~m}^{2}$, con un frente de $4 \mathrm{~m}$ y $15 \mathrm{~m}$ de profundidad, y una superficie construida de 38,18 $\mathrm{m}^{2}$ en un nivel. El programa arquitectónico incluye: 1 dormitorio, sala, comedor, cocineta, patio de servicio, estacionamiento para un auto y pequeño jardín trasero.

Modelo Cedrón, tiene una superficie de terreno de $60 \mathrm{~m}^{2}$ con un frente de $4 \mathrm{~m}$ y $15 \mathrm{~m}$ de profundidad, y una superficie construida de $60,72 \mathrm{~m}^{2}$ 
en dos niveles. El programa arquitectónico incluye: 2 dormitorios, sala de TV, estudio, sala, comedor, cocineta, patio de servicio, estacionamiento y jardín trasero.

Los materiales con que están construidos y terminados ambos modelos de casas son: muros de tabique y losas de concreto, recubiertos de aplanado de mortero y pisos de loseta.

Las casas del fraccionamiento habitacional en cuestión se encuentran en un área periurbana, a una distancia aproximada de 1,5 km de Almoloya de Juárez, sobre antiguos terrenos de cultivo (Figura 5).

Este conjunto estuvo a cargo del Consorcio Hogar S.A. de C.V., compañía fundada en 1996, que tiene como objetivo atender el sector de compradores de vivienda cuyo rango de ingreso mensual fluctúa entre 2,5 y 12 salarios mínimos.

\section{Resultados}

Los habitantes de las casas de este fraccionamiento fueron analizados por medio de entrevistas estructuradas y de profundidad. Los resultados de esta fase de la investigación aportan evidencias claras de la problemática generada por estos espacios, como se expone a continuación.

\section{Análisis cuanti-cualitativo}

Sentido de satisfacción personal asociada al espacio o lugar

El sentido de satisfacción personal asociada al espacio o lugar fue analizado con un abanico de conceptos como: felicidad, angustia, opresión, miedo y vacío. De esta variable, los mayores porcentajes (cuya suma es $63 \%$ ) oscilan entre una percepción de opresión o de angustia, mientras las respuestas menos frecuentes se inclinan hacia la felicidad, el miedo o el vacío (Figura 6).

\section{Sentido de afiliación}

La asociación es otra de las necesidades simbólicas del hombre, sentirse parte de un grupo, pero especialmente de un grupo próximo, cerrado y propio. Se pensaría que ello se cumple de alguna manera con los angustiados espacios que fuerzan esta "unión", ya que, al carecer de espacios íntimos, los lugares comunes se convierten en el refugio; sin embargo, los resultados muestran lo contrario (Figura 7). Asimismo, otro de los conceptos destacados es el de esperanza, y esto se puede explicar bajo la idea de que las casas en su mayoría no son propias, hecho que genera la percepción de que la condición descrita es transitoria.

\section{Sentido de protección y defensa}

Existen muchas referencias antropológicas que sustentan la necesidad de que, ante la percepción de vulnerabilidad, el hombre requiere sentirse protegido. Este aspecto no parece estar cubierto en este conjunto habitacional, ya que el concepto de "vandalismo" fue reiterativo en un $38 \%$, en contraste con el de seguridad (34\%) o el de vigilancia (17\%) (Figura 8).

\section{Sentido de reconocimiento}

El reconocimiento es una de las necesidades que más se ha privilegiado en la era consumista, ya que de ahí se derivan varias teorías de la mercadotecnia. Existe en cada persona una necesidad de sentirse apreciado, de poseer, tener prestigio y destacarse de entre los demás, pero ello se ha entendido como el posicionamiento económico que se tiene sobre los demás. La idea general de este prestigio se construye con posesiones materiales muy evidentes, como casa o auto, seguidas de artículos como aparatos eléctricos, celulares y ropa.
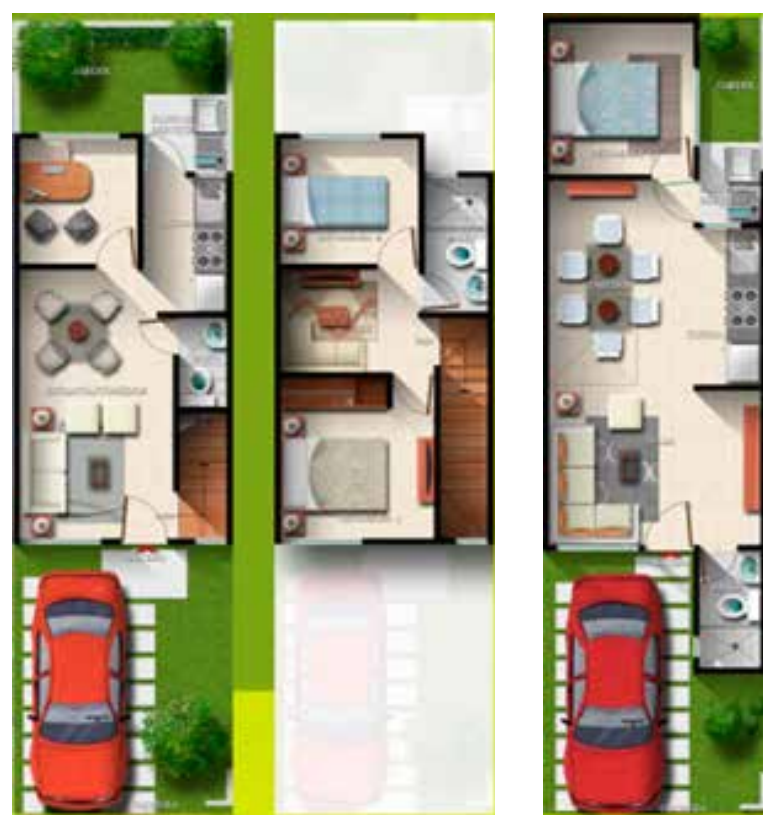

(4) Figura 4. Planta arquitectónica de los Modelos Malva (izquierda) y Modelo Cedrón (derecha) Fuente: Reyes (2015).

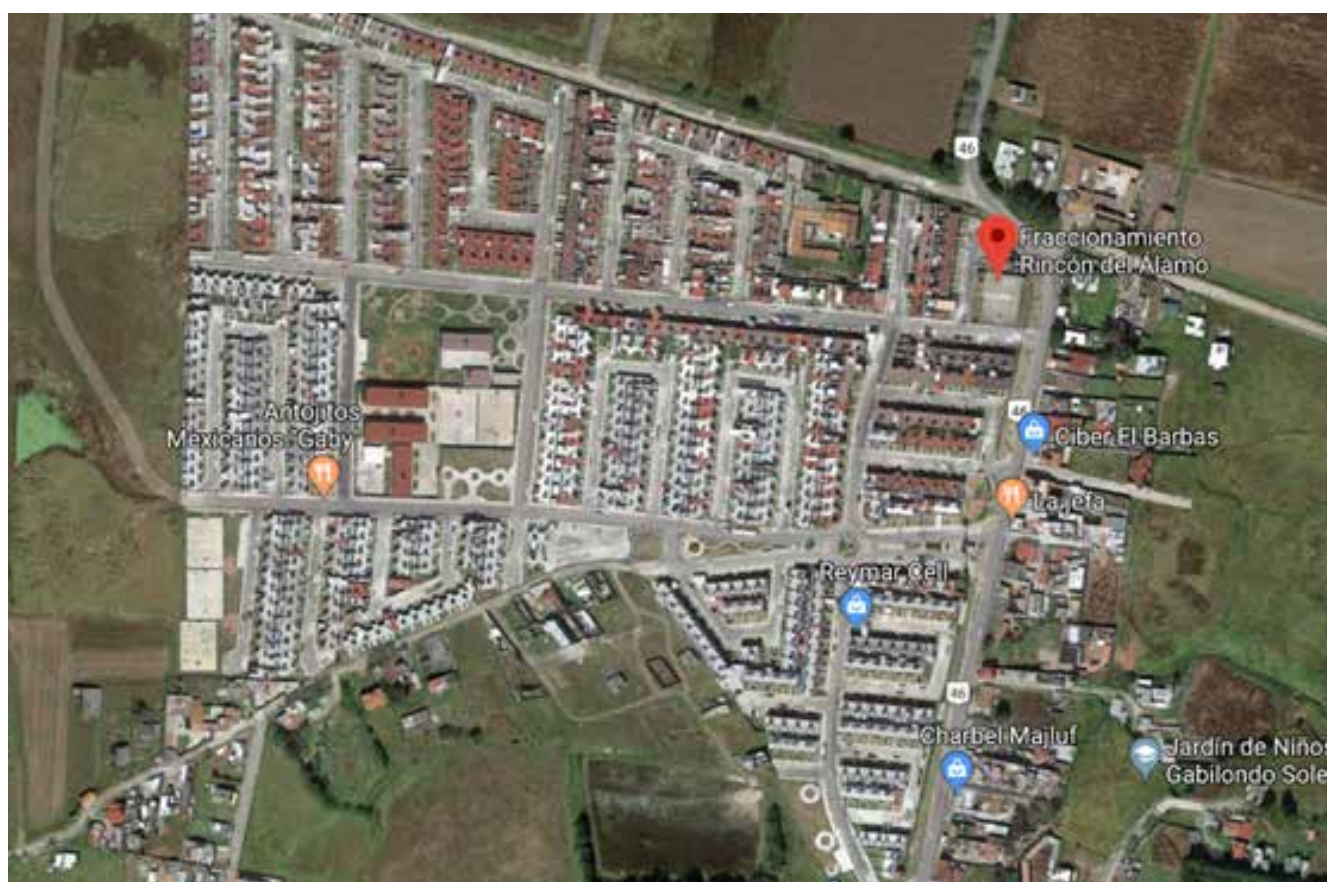

(A) Figura 5. Vista aérea del 2015 donde se aprecia que las casas del fraccionamiento Rincón del Álamo están ubicadas en terrenos periurbanos aislados Fuente: Google maps, 2015. 
Los conceptos presentados como: bienestar, carencia, superación de crisis y auge se encuentran ligados con la autovaloración y el respeto a sí mismo. Los resultados arrojaron que en un $35 \%$ la gente se percibe en una situación de carencia; esto se concentró sobre todo en aquellos habitantes que viven en el Modelo Malva, de dimensiones reducidas considerables. Esto se suma a la idea de crisis con un $20 \%$; nuevamente se privilegia la percepción negativa que se tiene de las casas del fraccionamiento. Finalmente, fueron reducidas las respuestas que se inclinaron hacia la idea de bienestar, superación y auge (Figura 9).

\section{Sentido de pertenencia y arraigo con el entorno}

La necesidad de pertenencia y arraigo nos determina como personas, en ello radica la actitud que asumimos con aquello que consideramos propio o no. Cuando algo es considerado nuestro, existe un esmero por su cuidado y por proteger el vínculo. Si existe desapego, las actitudes negativas proliferan, por ser el enfrentamiento con lo extraño y lo ajeno.

Cuando este sentido de pertenencia y arraigo no existe aparecen desajustes personales y fenómenos que manifiestan la inconformidad de la persona. Los conceptos que se presentaron fueron: México, Toluca, Almoloya o ninguna, con la intención de indagar cómo se percibe el vínculo de las casas de fraccionamiento con algunas de

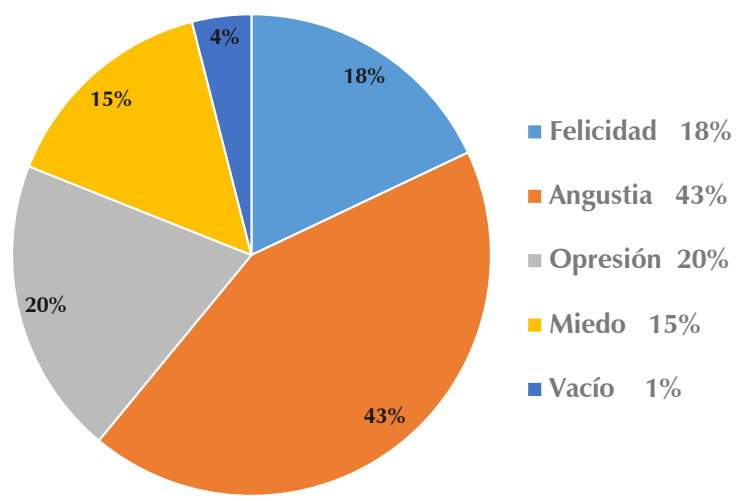

(A) Figura 6. Sentido de satisfacción asociada al espacio o lugar Fuente: elaboración propia, 2015

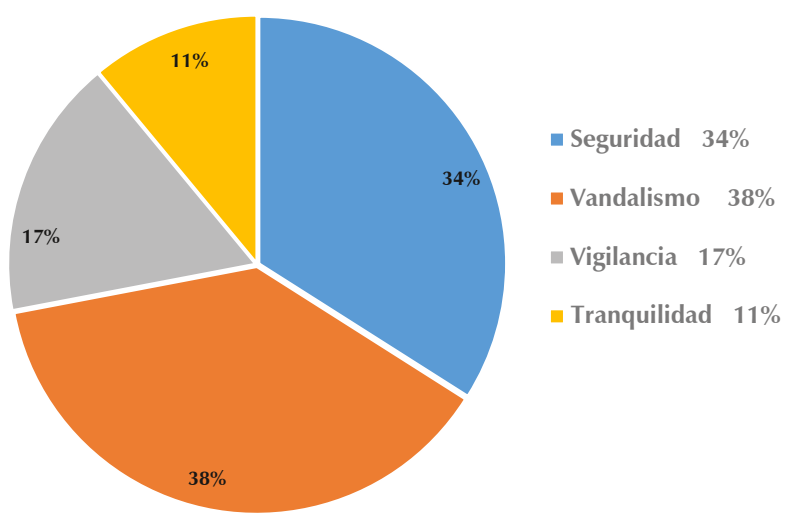

(A) Figura 8. Sentido de protección, defensa y vigilancia Fuente: elaboración propia, 2015 estas poblaciones, y si esta interpretación se anida en un nivel micro o escala a un nivel macro. Los resultados mostraron que la mayoría no siente apego por el poblado más próximo, que es de hecho en donde se ubican las casas del fraccionamiento, es decir Almoloya de Juárez (29\%).

Existe la evidencia de un mayor arraigo hacia la ciudad de Toluca (36\%), ya que varios de ellos expresaron ser ahí donde realizan el mayor número de actividades, siendo para ellos Almoloya de Juárez (poblado cercano) una especie de ciudad satélite. México, de ambigua interpretación por referirse igualmente a la denominación del estado o del país, obtuvo escasa frecuencia (10\%) y la opción de ninguna alcanzó un $25 \%$, lo que corrobora la falta de vínculo con el espacio que se habita (Figura 10).

\section{Sentido de proximidad con el otro}

Así como el arraigo, el sentido de proximidad con el otro complementa también la idea de vivir en sociedad. Para la idea de reconocimiento de sí mismo es necesaria una construcción social que reafirme al hombre, que le haga sentirse aceptado en un grupo social, donde la familia es una célula básica que se complementa en núcleos cada vez mayores, como el grupo de amigos, los compañeros de trabajo, los vecinos, etc. La casa podría considerarse un escenario de estos vínculos sociales, inicialmente en el seno de una familia $y$, posteriormente, de amistades, vecinos, etc. En

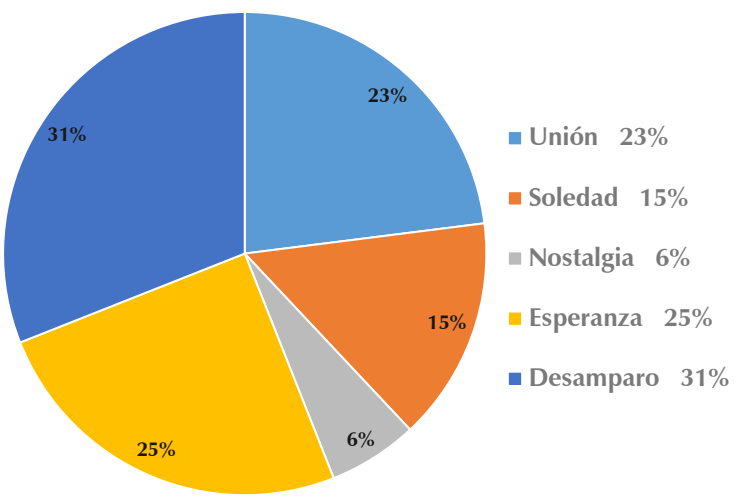

(A) Figura 7. Sentido de afiliación Fuente: elaboración propia, 2015.

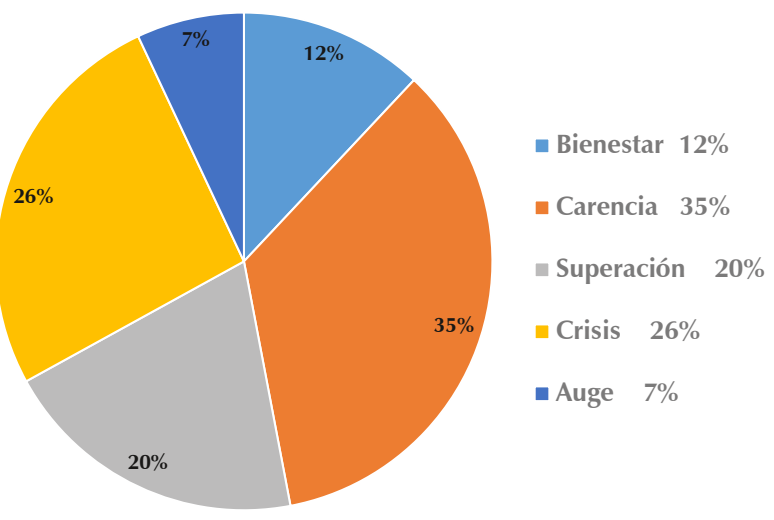

(A) Figura 9. Sentido de reconocimiento Fuente: elaboración propia, 2015. 
este sentido, la idea de proximidad y cercanía se contrastó con la de hacinamiento, con el fin de comprobar que la distancia física no es considerada necesariamente en un sentido positivo. La hegemonía del concepto de hacinamiento (nuevamente concentrada mayormente en los habitantes del Modelo Malva) cubrió en un 38\% la frecuencia de respuestas, mientras la proximidad y cercanía, aparentemente ideas cercanas, no fueron relacionadas metafóricamente con las casas de Rincón del Álamo. La idea de lejanía, considerada también como un concepto negativo en un hogar, tuvo una frecuencia de $35 \%$, por encima de proximidad y cercanía que no rebasaron un 15 y $12 \%$ respectivamente (Figura 11).

\section{Sentido de satisfacción de aspectos físico-mentales}

Sin ser factores específicamente fisiológicos como comer, dormir o asearse, la salud, la enfermedad, el deporte y la pasividad están relacionados con condiciones de tipo físico, aunque también mental. Existe una asociación entre la salud mental y los factores simbólicos, dado que ambos resultan trascendentales en la conformación de la idea de sí mismo y el autorreconocimiento. Las respuestas aquí analizadas pretenden una visión global que complemente lo analizado en el nivel de satisfacción asociada al lugar, al tiempo que se puede asumir como una evidencia que señale si la gente considera que dentro o cercano a las casas del fraccionamiento cuentan

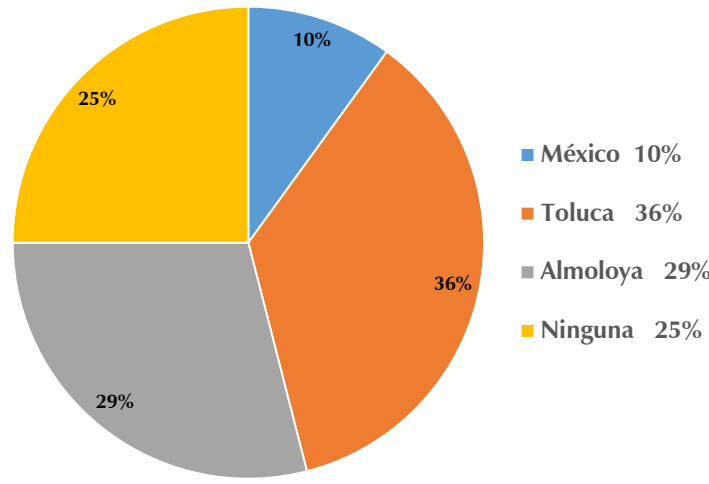

(A) Figura 10. Sentido de pertenencia y arraigo con el entorno

Fuente: elaboración propia, 2015.

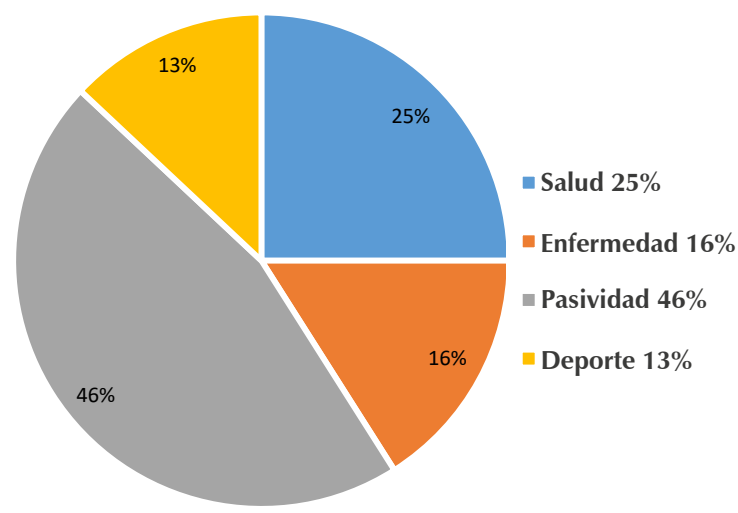

(A) Figura 12. Sentido de satisfacción de aspectos físicomentales

Fuente: elaboración propia, 2015. con los espacios de salud (para practicar deporte, para cuidar su salud en otros sentidos) necesarios para cubrir este aspecto.

Los conceptos presentados fueron: salud, enfermedad, pasividad y deporte, a lo que la respuesta general fue sentirse más estrechamente ligados con el término de pasividad (46\%), que con los conceptos extremos como salud y deporte o enfermedad (Figura 12).

\section{Sentido de asociación del espacio con su uso psicológico y social}

La connotación que se asocia a la casa es una muestra clara de lo que en ella acontece. Contrariamente a lo esperado fue más asociada al trabajo que al descanso: un $38 \%$ contra un $19 \%$, respectivamente. El otro concepto dominante fue el de necesidad, por lo que la casa, más que considerarse como un refugio, un lugar que cumpla con sus expectativas, se convierte en una manera de cubrir medianamente una necesidad. Ello se reafirma al momento en que, en una entrevista una persona dijo que lo importante era "tener un techo" (Figura 13).

\section{Análisis cualitativo}

Para realizar el análisis cualitativo fueron realizadas tres entrevistas a profundidad a tres personas de diferentes segmentos:

1. Señora Susana Ramírez, habitante del Modelo Malva, edad aproximada 45 años, sexo femenino, casada, 2 hijos y esposo. Ocupación

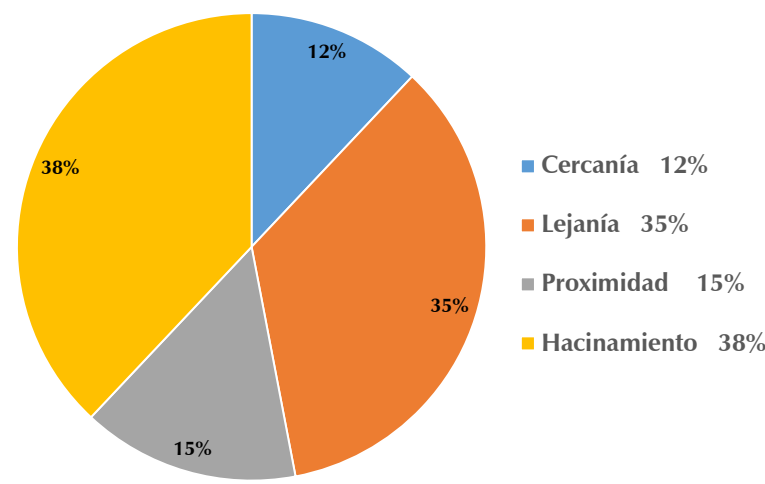

A Figura 11. Sentido de proximidad con el otro Fuente: elaboración propia, 2015.

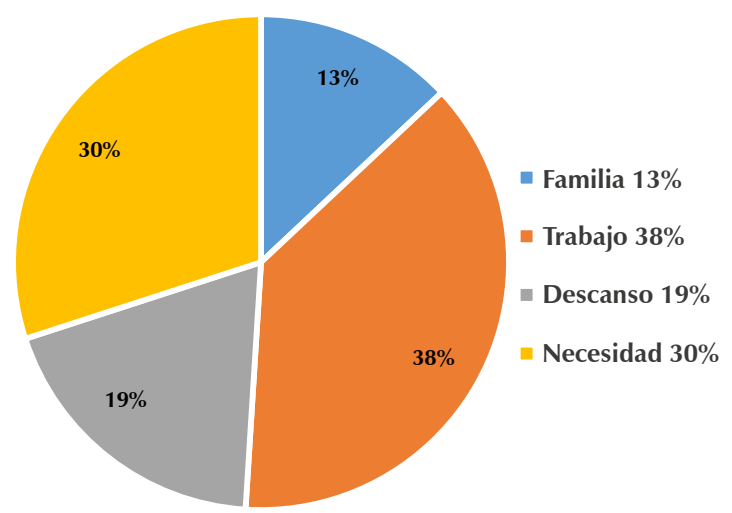

(A) Figura 13. Sentido de asociación del espacio con su uso psicológico y social Fuente: elaboración propia, 2015. 
comerciante, esposo taxista, procedencia Distrito Federal.

2. Señora Sandra García, habitante del Modelo Cedrón, edad aproximada 30 años, sexo femenino, casada, 2 hijas y esposo. Ocupación ama de casa, esposo empleado, procedencia Michoacán.

3. Joven Pedro Cortés Jiménez, habitante del Modelo Malva, edad aproximada 23 años, sexo masculino, soltero. Ocupación empleado de Gobierno, procedencia Toluca.

Cada una de estas personas fue analizada, durante y posteriormente a la entrevista, con base en los elementos contextuales o situacionales con la intención de identificar oposiciones (que pudieran ser impedimentos para la obtención de información fidedigna), ya que es importante considerar que cada una de las declaraciones parte de sustratos sociopsicológicos y emocionales.

1. La señora Susana Ramírez destacó desde un primer momento que ella no era la dueña y que ya estaba por cambiarse de casa a una "más cercana a Toluca". Ello generó una actitud crítica y de distanciamiento con la problemática, lo que también se puede traducir como una negación a ser considerada parte de esta.

2. La señora Sandra García corresponde justo al caso contrario del anteriormente descrito. Ella es una de las primeras habitantes de las casas del fraccionamiento. Es posible que esta antigüedad haya generado en ella un sentido de arraigo, ya que ella sí es propietaria. Este arraigo le hace percibir la problemática de un modo minimizado. Se aprecia incluso una postura a la defensiva, en la que pretende recrear una situación altamente positiva frente a las carencias evidentes.

3. El joven Pedro Cortés Jiménez manifiesta una percepción masculina, con un sentido altamente pragmático de la problemática. El arraigo no es una característica general en los adultos jóvenes, por ser aún hijo de familia. Su postura es crítica, fresca y honesta.

El siguiente análisis ha sido segmentado según las variables simbólicas señaladas en el análisis de las entrevistas dirigidas.

\section{Sentido de satisfacción personal asociada al espacio o lugar}

Es posible encontrar evidencias de la falta de satisfacción con la experiencia de habitar el lugar, que se acrecienta en el caso de los habitantes del Modelo Malva, ya que al contar con un solo dormitorio recurren a este modelo en el que prevalece la situación económica sobre las expectativas de vivienda. Ello implica incomodidades, así como sentimiento de angustia y opresión, lo que coincide con los resultados obtenidos en las entrevistas cuanti-cualitativas.
Los habitantes refieren ideas como: "Los espacios no se usan de manera convencional, ya que por ejemplo la sala-comedor no se usa como tal porque los muebles no caben [...] No tenemos áreas privadas, solo la recámara que ocupamos mi esposo y yo" (Susana Ramírez).

Por otro lado, la necesidad de optimizar el espacio ha generado que las familias utilicen los espacios para usos mixtos, no simultáneos: "Mis hijos duermen en su cama junto al comedor" (Susana Ramírez), así como "para lavar está la zotehuela y para tender la ropa está ese mismo espacio y ocupamos también la cochera de enfrente" (Susana Ramírez).

La insatisfacción que algunos de los participantes señalaron no es estrictamente espacial, sino de estilo de vida: "Mis hijos asisten a la escuela en Toluca, y sí resulta pesado estarlos llevando diario, nos tardamos casi 1 hora u hora y cuarto, y es que hay mucho tráfico" (Susana Ramírez).

Asimismo, el joven Pedro Cortés apuntó que: "Me levanto como a las 6, me baño en las noches porque si no, no nos da tiempo, porque vivo con mis papás y mi hermana".

\section{Sentido de afiliación}

En este sentido, lo ideal sería que un espacio fuera propicio para generar grupos humanos más unidos y armoniosos. Sin embargo, las escasas dimensiones parecen ser un elemento de "unión" física mas no emocional. Al respecto, la señora Susana Ramírez comenta: "la convivencia de la familia se da con relación al espacio, como este es pequeño, pues se platica más, pero como ya están en la adolescencia cada quien quiere su espacio [...] En cuanto a la demás familia, mis hijas mayores, es imposible que vengan porque no hay espacio... aquí no cabemos".

En contraste con lo señalado por la señora Ramírez, la señora García, si bien reconoce la precariedad en las dimensiones de las casas, asume una postura mucho más positiva: "el mismo espacio pequeñito hace que convivamos más, que estemos más cerca".

Las relaciones generadas en el mismo escenario, dependiendo de su nivel de profundidad, pueden evidenciar o bien conformidad o adaptación, o sentido de pertenencia.

La actitud de adaptación de denota en la siguiente afirmación: "En general nos llevamos bien, yo digo que nos soportamos [los vecinos]. Algunos son muy chismosos, otros sucios, otros hacen mucho ruido con su música, a otros les gusta hacer 'talacha' en la calle y parece taller, pero ni modo. Nos aguantamos unos a otros" (Pedro Cortés).

En cuanto al sentido de arraigo que se puede desarrollar, este puede provocar un cambio en la perspectiva de la problemática, ya que al generar lazos (amistosos, amorosos, etc.), el vínculo social se sobordina a las incomodidades vividas: "A los hijos les gusta [vivir aquí] [...] Para ellos la parte del espacio no es tan importante, sino la 
parte de convivencia. A mí en lo personal no me gustaría que crecieran aquí" (Susana Ramírez).

\section{Sentido de protección y defensa}

La necesidad de sentirse protegidos en esta época en la que, particularmente en el valle metropolitano de Toluca se presentan altos índices de delincuencia, ha sido un factor que: a) por un lado ha acrecentado la segmentación social (la aparición primera de muros perimetrales en residenciales de alto nivel económico y la estrecha vigilancia con que se maneja el acceso de los mismos, representa una manera de marginación con los que no pertenecen a ese sector), y b) por el otro lado ha producido nuevas aspiraciones por parte del sector segregado que pretenden estar "tan seguros como las clases altas". Esto ha generado que los fraccionamientos también ofrezcan "seguridad" a través de muros perimetrales, cercas y casetas de vigilancia que, sin embargo, al contrario de las originales de los residenciales, aquí solo se presentan como simulación, ya que no siempre existen y no corresponden al estilo de vida de las clases bajas: "desgraciadamente el hecho de que nos pusieran la reja como seguridad perjudicó algunas cosas, en este caso el camión de la basura no entra a la calle" (Sandra García).

Las casetas de vigilancia no ejercen control de acceso (el acceso es libre) y los muros se convierten en obstáculos para la vida cotidiana, esto se refleja en las siguientes afirmaciones: "pues está la caseta de vigilancia a la entrada, pero eso no garantiza que gente extraña se meta. Ha habido algunos problemas de robos de gente extraña que se mete al fraccionamiento" (Pedro Cortés); "yo he sabido de dos o tres casos de saqueos en las casas, también porque hay muchas deshabitadas y robos pequeños: a algunos les robaron el boiler, a otro le vaciaron su casa mientras la persona estaba trabajando" (Sandra García).

\section{Sentido de reconocimiento}

El reconocimiento implica la importancia que les damos a los demás, así como la importancia del concepto que el "otro" tenga de uno. La impresión que demos ante los demás afecta invariablemente la autoestima. Dada la precaria situación espacial de las casas en estudio, la experiencia de las mismas dista mucho de ser lo que se oferta en su publicidad.

Como se ha mencionado, los espacios tienen que adaptarse a otros usos, lo que generalmente va en detrimento de su función y aspecto. Este último altamente relacionado con la autoestima: "Atrás hay un patiecito con lavadero, pero mi mamá dice que la ropa no le cabe para tenderla y la tiende enfrente, y yo siento que esto se ve un poco feo" (Pedro Cortés).

"Me siento mal, porque las casas son muy pequeñas, no tienen el espacio necesario. Son como ratoneras. Y no creo que sea lo que todos deseamos, pero es lo que se puede" (Pedro Cortés).

\section{Sentido de pertenencia y arraigo con el entorno}

Como se ha apreciado en este análisis, existen varios factores para generar sentido de arraigo, entre ellos se ha destacado la cercanía con el lugar, el desarrollo de relaciones en este, la atracción personal con el lugar (por asociaciones mentales), etc.

La cercanía con Almoloya de Juárez, un poblado que en el 2010 reportó una población de 3.091 habitantes (INEGI, 2010), es percibida por los habitantes de las casas en estudio con dos orientaciones: a) un lugar entrañable, tranquilo y acogedor, lo que corresponde a la afirmación: "nos gustaron las casas del fraccionamiento, ya que están cerca del pueblito y eso nos gustó. Cuando venimos a visitar el fraccionamiento esto ni estaba, apenas estaban las casas muestra" (Sandra García). Este punto de vista deja claro que el motivo principal de la elección de compra de la casa fue emocional, ya que su casa físicamente no existía, y sin embargo ellos la adquirieron solo por estar cercana a un lugar que les pareció acogedor y típico. Bajo esta perspectiva se busca generar un vínculo emocional de arraigo con el lugar.

La segunda orientación posible es: b) un lugar poco desarrollado y alejado de la ciudad, concepto que, en contraste con la perspectiva anterior, genera un sentido de distancia y alejamiento que impide la generación del vínculo emocional: "salimos de aquí todos a las 6:30 a.m. y llegamos a la casa como a las 8 de la noche, ya nada más para cenar. Prácticamente no estamos aquí" (Susana Ramírez), lo que se reafirma cuando los habitantes dicen prácticamente no vivir en su casa: "En general yo no permanezco mucho tiempo en la casa, yo la ocupo más para dormir" (Susana Ramírez) y "me visto, me arreglo y me voy como a las 7:00, porque mi trabajo está por Lerma y si no, no llego. Al regreso llego como a las 8 de la noche a cenar y bañarme y así todos los días" (Pedro Cortés).

En la misma idea, sobre lo incómodo de la distancia entre las casas del fraccionamiento y otras zonas, en cuanto al sentido de arraigo, Pedro Cortés expresa: "Hay pequeñas tienditas para lo necesario, pero para lo demás hay que ir a Almoloya o a Toluca".

Este distanciamiento también es un resultado de la posesión o no del inmueble, como se aprecia: "Aquí hay varias casas que no se usan, todas tienen dueño, pero solo les ponen protecciones y no las usan. Yo la rento" (Susana Ramírez). Igualmente importante es percibir que las personas que se encuentran en posesión presentan más sentido de pertenencia que aquellos que solo se sienten "de paso": "Nosotros ya tenemos viviendo acá como tres años, cuando yo llegué estaban habitadas como cuatro casas" (Sandra García).

Finalmente, es posible inferir que las variables funcionales también pueden provocar un fenómeno sociocentrífugo, al tiempo que el distanciamiento puede ser generado por una intencional desvinculación de las personas que habitan las 
casas del fraccionamiento: "Mis hijas tienen actividades por las tardes de manera que no las llevo por aquí al parque del fraccionamiento" (Sandra García); esta postura muestra una intencional desvinculación de la entrevistada (dueña de una casa Modelo Cedrón) que muestra una postura de superioridad y desdén sobre los habitantes del modelo más modesto (Malva).

\section{Sentido de proximidad con el otro}

Es manifiesta la importancia de la proxémica al interior de la casa, en donde la proximidad es un elemento simbólico deseable entre los miembros de una familia, pero no cuando las características físicas provoquen hacinamiento. Este fenómeno es repetitivo en el Modelo Malva, al corresponder al modelo más económico pero que al mismo tiempo, al ofrecer un solo dormitorio, no corresponde a la realidad de la generalidad de familias mexicanas: "Somos un matrimonio con dos hijos, pero tener una sola recamara es incómodo por el espacio" (Susana Ramírez), a lo que se suma otra afirmación: "mi cama, que está en la sala porque el cuarto lo usan mis papás y mi hermana. Nos reunimos para comer en el comedorcito. Cocina prácticamente no hay, ni sala, no caben. Además, la sala es más bien para visitas y pues casi no tenemos porque no hay ni dónde sentarlos" (Pedro Cortés).

La necesidad espacial no se reduce a un espacio dimensional sino simbólico: "Pues como cada quien tiene sus cosas, y casi siempre estamos en la calle entre semana es poca [la interacción], en fin de semana nos vemos más pero es incómodo estar un poco amontonados. Yo quisiera mi recámara" (Pedro Cortés). En estas casas no se satisface la necesidad de un espacio personal e íntimo.

Sentido de satisfacción de aspectos físico-mentales

Se encontró que las casas del fraccionamiento, según las entrevistas, tampoco satisfacen necesidades como la dotación de un espacio para recreación, pues estos son lugares que no se encuentran en condiciones óptimas o se han tornado en depósitos de restos de la obra de construcción; al respecto la señora Sandra García dice: "Al fondo, en la que era la entrada principal hay una zona que pretendía ser como un parquecito, porque había una casita para los niños y eso, pero me parece que no está funcionando. La verdad es que nosotras no acostumbramos mucho a ir hasta allá, creo que ya quitaron los juegos".

Las canchas deportivas son vistas también como un recurso de búsqueda de espacio, una respuesta al problema espacial y proxémico descrito, ello queda manifestado cuando la entrevistada refiere que su hijo "tiene que" (lo que representa más obligatoriedad que placer en la práctica,) pues dice: "mi hijo pequeño se 'tiene' que ir a jugar porque no le gusta estar 'metido' en la casa y se va a las canchas a jugar" (Susana Ramírez); o bien obligados por las condiciones de las privadas: "aquí no se puede jugar mucho porque los vecinos se molestan porque les pegan a los carros o las ventanas se rompen porque no tienen protección" (Susana Ramírez).

\section{Sentido de asociación del espacio con su uso psicológico y social}

Como resultado de la entrevista se aprecia que, para los entrevistados, las casas no constituyen un refugio ni lugar de encuentro social ni familiar, debido a sus características: "En cuanto a la demás familia, mis hijas mayores, es imposible que vengan porque no hay espacio. Cuando nos reunimos les decimos que mejor en sus casas porque aquí no cabemos" (Susana Ramírez).

Su papel como refugio es igualmente vulnerable: "Los fines de semana los uso para descansar y trato de quedarme aquí pero luego no se puede porque mi papá pone el fútbol o la tele y mi hermana su música, o los vecinos su escándalo y luego mejor me salgo" (Pedro Cortés).

Los factores psicológicos y sociales no parecen ser apreciados como bien atendidos. A la pregunta expresa de cómo se percibe la experiencia de vida en Rincón del Álamo, la señora Susana Ramírez respondió: "Yo calificaría mi experiencia del 1 al 10 con un 6 , solo por tener la casa y con ella un techo en dónde vivir, pero la verdad no está bien"; lo que deja la certeza de que la parte física más primitiva: "techo en donde vivir", es lo único que se considera satisfecho.

\section{Discusión}

Los resultados obtenidos en las entrevistas permiten dejar en claro que el aspecto espacial es uno de los que más determinan el sentimiento asociado al lugar, que en este caso fue la opresión, al tiempo que existe un sentido de desamparo como consecuencia de la falta de un espacio personal e identitario.

Cierto es que se trata de casas ubicadas en un fraccionamiento bardeado y que cuenta con caseta de vigilancia a la entrada, pero el hecho de ir fragmentando el fraccionamiento al interior del mismo (al generar privadas dentro de un fraccionamiento bardeado) permite concluir que las bardas no se perciben como suficientes medios de protección. También se observa que la caseta ubicada a la entrada no cumple con una labor de control y seguimiento, lo que se traduce en un espacio de acceso libre y descontrolado, que se torna en una concepción de espacio inseguro e indefenso.

La idea de carencia y crisis se concentró más en aquellos habitantes que viven en el Modelo Malva, de considerables dimensiones reducidas.

Por ende, no hay arraigo con la zona. Existe la evidencia de un mayor arraigo hacia la ciudad de Toluca que hacia Almoloya (su población más cercana), ya que varios de ellos expresaron ser ahí donde realizan el mayor número de actividades; Almoloya de Juárez es percibida como una especie de ciudad satélite.

El concepto de hacinamiento, sobre todo en los habitantes del Modelo Malva, fue más frecuente que el de proximidad y cercanía. La idea de lejanía, considerada como un concepto negativo en un hogar, tuvo también mayor frecuencia. 
Otro concepto destacado fue el de pasividad, en comparación con la salud, el deporte y la enfermedad. Ello resulta congruente con lo descrito por los pobladores: existen algunas canchas cercanas para practicar deporte, pero de alguna manera están restringidas a los adolescentes, ya que no existen parques recreativos. Tampoco existen clínicas ni hospitales cercanos a las casas del fraccionamiento, por lo que salud, deporte o enfermedad fueron conceptos relegados.

Al no concebir su casa como un refugio para el descanso, los pobladores la consideran más ligada a su trabajo. La asociación pudo venir más en términos del tiempo de dedicación a cada aspecto, es entonces lógico que haya predominado la idea de trabajo sobre la de descanso.

\section{Conclusiones}

El análisis permitió responder a la hipótesis originalmente planteada, de que además de las necesidades estéticas y funcionales de una casa, esta debe cubrir necesidades antrópicas, psicológicas y emocionales.

Se concluye con ello que la generación de vínculos simbólicos es menor en la medida que los pobladores no son habitantes de "tiempo completo", por lo que el vínculo se estrecha con la permanencia. Los habitantes que rentan suelen desarrollar por inercia un sentido de desarraigo. El problema de precariedad en los espacios impide una apropiación particular del mismo, sin embargo, el hombre es capaz de generar un vínculo con el espacio en escala mayor ("mi casa").

Por otro lado, las soluciones universales son una falacia; entre más se aprecia la masificación de los espacios, mayor es la demanda de personalización de los habitadores. Una necesidad simbólica del ser humano es distinguirse de los demás como muestra de una autorreafirmación. La necesidad de identidad se pue- de satisfacer con la diferencia: desde pequeñas modificaciones en fachadas como color, forma de ventanas, etc., hasta inmersiones espaciales como la propuesta de muros y muebles flexibles, abatibles giratorios, donde la ambigüedad espacial sea una respuesta simbólica.

Los espacios deberían mostrarse flexibles, optar por principios de plantas libres y dotar de la posibilidad de muros flexibles, abatibles o giratorios, que abran o cierren los espacios dependiendo de sus usos, adaptándose a la dinámica cambiante de la familia sobremoderna.

Resulta importante incursionar en el diseño de mobiliario flexible y adaptable, incluir a los diseñadores en la problemática dado que el problema arquitectónico de espacio no es solo dimensional sino de usabilidad.

Finalmente, el autorreconocimiento, hoy más que nunca, en la generalidad de las personas, se ve reflejado en el nivel económico en el que el propio individuo se reconozca. Ello detona en la generación de privadas al interior del fraccionamiento, y la existencia de casetas de vigilancia que resultan simbólicas, ya que por sus características y resultados no protegen ni controlan nada, pero a los habitantes les brindan seguridad y les dan la sensación de vivir en un conjunto residencial donde estas utopías sí son reales (espacios verdaderamente fortificados, electrificados, con acceso condicionado, etc.). Asimismo, los ubica en un estrato superior al de quienes no viven en estas condiciones.

Como se aprecia, la consideración de "otro" tipo de necesidades al diseñar y desarrollar una mirada antropológica de casa en la sobremodernidad permite una reconcepción de los espacios bajo un esquema antrópico, y su relación simbólica con el usuario llevará a una nueva dimensión humana el quehacer del arquitecto que atienda necesidades psicológicas y emocionales.

\section{Referencias}

Augé, M. (2002). Los "no lugares" espacios del anonimato. Una antropología de la sobremodernidad. Barcelona: Gedisa.

Baudrillard, J. (1988). The ecstasy of Communication. New York: Semoitext(e).

Coppola Pignatelli, P. (1997). Análisis y diseño de los espacios que habitamos. México: Árbol.

Corbusier, L. (1978). Hacia una arquitectura. Barcelona: Poseidón.

De Hoyos Martínez, J. (2010). La casa: origen de la conformación territorial. Toluca: Gobierno del Estado de México.

Geertz, C. (1996). Interpretación de las culturas. Barcelona: Gedisa.

Goolgle maps. (2015). [Mapa de Fraccionamiento Rincón de Álamo, México en Google maps] Recuperado de https://www. google.com.mx/maps/place/Fraccionamiento+Rinc\%C3\%B3n+del $+\%$ C3\%81lamo/@19.3801982,-99.7629941,16.08z/ data $=! 4 \mathrm{~m} 5$ !3m4!1s0x85d279a34490e81f:0x103fofod8e283ca0!8m2!3d19.380376 !4d-99.757495?dcr $=0$
Ibelings, H. (1998). Supermodernismo. Arquitectura en la era de la globalización. Barcelona: Gustavo Gili.

Jacobs, J. (2011). Reconsidering Jane Jacobs. Chicago: Planners Press.

Jung, C. (2009). Arquetipos e inconsciente colectivo (Miguel Murmis, trad.). Barcelona: Paidós.

Maslow, A. H. (2009). El hombre autorrealizado: hacia una psicología del ser. Barcelona: Kairos.

Morales, J. (1999). Arquitectónica. Sobre la idea y el sentido de la arquitectura. Madrid: Biblioteca Nueva.

Muntañola, J. (1996). La arquitectura como lugar. México: Alfaomega.

Muntañola, J. (2009). Topogénesis, fundamentos de una nueva arquitectura. Barcelona: Ediciones UPC.

Narváez Tijerina, B. (2004). Teoría de la arquitectura. Aproximación a una antropología de la arquitectura y la ciudad. México: Trillas.
Oliveras, J., Montaner, J., De Sola Morales, M. y Ramón, A. (2000). Introducción a la arquitectura, conceptos generales. Barcelona: Ediciones UPC.

Papanek, V. (2014). Diseñar para el mundo real. Barcelona: Akal.

Reyes Viurquez J. M. (2015). Fundamentos simbólicos en el diseño de la casa en la sobremodernidad. Una evaluación de los espacios de la Casa en el Valle Metropolitano de Toluca. [Figura]. (Tesis de maestría). Universidad Autónoma del Estado de México, México. Recuperado de http://ri.uaemex.mx/handle/20.500.11799/40850/ browse?type $=$ subject $\&$ value $=$ Evaluaci $\%$ C3\%B3n+de+espacios

Rossi, A. (1982). The architecture of the city. Cambridge, Mass: MIT Press. 


\section{Enfoque y alcance}

La Revista de Arquitectura (Bogotá) (ISSN 1657-0308 Impresa y E-ISSN 2357-626X en línea) es una publicación seriada de acceso abierto, arbitrada mediante revisión por pares (doble ciego) e indexada, en donde se publican resultados de investigación originales e inéditos.

Está dirigida a la comunidad académica y profesional de las áreas afines a la disciplina. Es editada por la Facultad de Diseño y el Centro de Investigaciones (CIFAR) de la Universidad Católica de Colombia en Bogotá (Colombia).

La principal área científica a la que se adscribe la Revista de Arquitectura (Bogotá) según la OCDE es:

Gran área: 6. Humanidades

Área: 6.D. Arte

Disciplina: 6D07. Arquitectura y Urbanismo

También se publican artículos de las disciplinas como 2A02, Ingeniería arquitectónica; 5G03, Estudios urbanos (planificación y desarrollo); 6D07, Diseño.

Los objetivos de la Revista de Arquitectura (Bogotá) son:

- Promover la divulgación y difusión del conocimiento generado a nivel local, nacional e internacional

- Conformar un espacio para la construcción de comunidades académicas y la discusión en torno a las secciones definidas.

- Fomentar la diversidad institucional y geográfica de los autores que participan en la publicación.

- Potenciar la discusión de experiencias e intercambios científicos entre investigadores y profesionales.

- Contribuir a la visión integral de la arquitectura, por medio de la concurrencia y articulación de las secciones mediante la publicación de artículos de calidad.

- Publicar artículos originales e inéditos que han pasado por revisión de pares, para asegurar que se cumplen las normas éticas, de calidad, validez científica, editorial e investigativa.

- Fomentar la divulgación de las investigaciones y actividades desarrolladas en la Universidad Católica de Colombia.
Palabras clave de la Revista de Arquitectura (Bogotá): arquitectura, diseño, educación arquitectónica, proyecto y construcción, urbanismo.

Idiomas de publicación: español, inglés, portugués y francés.

Título abreviado: Rev. Arquit.

Titulo corto: RevArq

\section{Políticas de sección}

La revista se estructura en tres secciones correspondientes a las líneas de investigación activas y aprobadas por la institución, y dos complementarias, que presentan dinámicas propias de la Facultad de Diseño y las publicaciones relacionadas con la disciplina.

Cultura y espacio urbano. En esta sección se publican los artículos que se refieren a fenómenos sociales en relación con el espacio urbano, atendiendo aspectos de la historia, el patrimonio cultural y físico, y la estructura formal de las ciudades y el territorio.

Proyecto arquitectónico y urbano. En esta sección se presentan artículos sobre el concepto de proyecto, entendido como elemento que define y orienta las condiciones proyectuales que devienen en los hechos arquitectónicos o urbanos, y la forma como estos se convierten en un proceso de investigación y nuevo de conocimiento. También se presentan proyectos que sean resultados de investigación, los cuales se validan por medio de la ejecución y transformación en obra construida del proceso investigativo. También se contempla la publicación de investigaciones relacionadas con la pedagogía y didáctica de la arquitectura, el urbanismo y el diseño.

Tecnología, medioambiente y sostenibilidad. En esta sección se presentan artículos acerca de sistemas estructurales, materiales y procesos constructivos, medioambiente y gestión, relacionados con los entornos social-cultural, ecológico y económico.

Desde la Facultad. En esta sección se publican artículos generados en la Facultad de Diseño, relacionados con las actividades de docencia, extensión, formación en investigación o internacionalización, las cuales son reflejo de la dinámica y de las actividades realizadas por docentes, estudiantes y egresados; esta sección no puede superar el $20 \%$ del contenido.

Textos. En esta sección se publican reseñas, traducciones y memorias de eventos relacionados con las publicaciones en Arquitectura y Urbanismo.

\section{A Frecuencia de publicación}

Desde 1999 y hasta el 2015, la Revista de Arquitectura (Bogotá) publicó un volumen al año, a partir del 2016 se publicarán dos números por año en periodo anticipado, enero-junio y julio-diciembre, pero también maneja la publicación anticipada en línea de los artículos aceptados (versión Post-print del autor).

La Revista de Arquitectura (Bogotá) se divulga mediante versiones digitales (PDF, HTML, EPUB, XML) e impresas con un tiraje de 700 ejemplares, los tiempos de

Universidad Católica de Colombia (2018,
julio-diciembre).
Revista de Arquitectura (Bogotá),
20(2), I-I28. Doi: I0.I47/8
ISSN: 1657-0308
E-ISSN: 2357-626X
Especificaciones:
Formato: 34 x $24 \mathrm{~cm}$
Papel: Mate II5 g
Tintas: Negro y policromía

producción de estas versiones dependerán de los cronogramas establecidos por la editorial.

Los tiempos de recepción-revisión-aceptación pueden tardar entre seis y doce meses dependiendo del flujo editorial de cada sección y del proceso de revisión y edición adelantado.

Con el usuario y contraseña asignados, los autores pueden ingresar a la plataforma de gestión editorial y verificar el estado de revisión, edición o publicación del artículo.
A Canje

La Revista de Arquitectura está interesada en establecer canje con publicaciones académicas, profesionales o científicas del área de Arquitectura y Urbanismo, como medio de reconocimiento y discusión de la producción científica en el campo de acción de la publicación.

\section{Mecanismo}

Para establecer canje por favor descargar, diligenciar y enviar el formato: RevArq FP20 Canjes 
Universidad Católica de Colombia

Presidente

Édgar Gómez Betancourt

Vicepresidente - Rector

Francisco José Gómez Ortiz

Vicerrector Jurídico

Edwin de Jesús Horta Vásquez

Vicerrector Administrativo

Édgar Gómez Ortiz

Vicerrector Académico

Elvers Medellín Lozano

Director de Investigaciones

Edwin Daniel Durán Gaviria

Directora Editorial

Stella Valbuena García

\section{Facultad de Diseño}

Decano

Werner Gómez Benítez

Director de docencia

Jorge Gutiérrez Martínez

Directora de extensión

Adriana Pedraza Pacheco

Director de investigación

Hernando Verdugo Reyes

Director de gestión de calidad

Augusto Forero La Rotta

Comité asesor externo

Facultad de Diseño

Édgar Camacho Camacho

Martha Luz Salcedo Barrera

Samuel Ricardo Vélez
Facultad de Diseño

Centro de Investigaciones - CIFAR
Revista de acceso abierto

arbitrada e indexada

Publindex: Categoría B. Índice Bibliografico Nacional IBN.

Esci: Emerging Source Citation Index.

Doaj: Directory of Open Access Journals.

Redalyc: Red de Revistas Cientificas de América Latina y el Caribe, España y Portugal.

SciELO: Scientific Electronic Library Online - Colombia

Redib: Red Iberoamericana de Innovación y Conocimiento Cientifico.

Ebsco: EBSCOhost Research Databases.

Clase: Base de datos bibliográfica de revistas de ciencias sociales y

humanidades.

Latindex: Sistema Regional de Información en Línea para Revistas

Cientificas de América Latina, el Caribe, España y Portugal (Directorio

y catálogo).

Dialnet: Fundación Dialnet - Biblioteca de la Universidad de La Rioja.

LatinRev: Red Latinoamericana de Revistas Académicas en Ciencias

Sociales $y$ Humanidades.

Proquest: ProQuest Research Library.

Miar: Matrix for the Analysis of Journals.

Sapiens Research: Ranking de las mejores revistas colombianas según visibilidad internacional.

Actualidad Iberoamericana: (Índice de Revistas) Centro de Informació Tecnológica (CIT).

Google Scholar

Arla: Asociación de Revistas latinoamericanas de Arquitectura.

Editorial

Av. Caracas $N^{\circ} 46-72$, piso

Teléfono: 3277300 Ext. 5145

editorial@ucatolica.edu.co

www.ucatolica.edu.co

http://publicaciones.ucatolica.edu.co/

Impresión:

JAVEGRAF

Calle 46A No82-54 Int. 2

Bogotá, D. C., Colombia

http://www.javegraf.com.co/index.php

Agosto de 2018

\section{Revista de Arquitectura \\ (Bogotá)}

Director

Werner Gómez Benítez

Editor

César Eligio-Triana

Editores de sección

(1) Myriam Stella Díaz Osorio

(1) Carolina Rodríguez-Ahumada

(1) Anna Maria Cereghino Fedrigo

\section{Equipo editorial}

Coordinadora editorial

María Paula Godoy Casasbuenas mpgodoy@ucatolica.edu.co

Diseño y montaje

Juanita Isaza

juanaisaza@gmail.com

Traductoras

Inglés

Erika Tanacs

etanacs25@gmail.com

Portugués

Roanita Dalpiaz

roanitad@gmail.com

Correctora de estilo

María José Díaz Granados M.

mariajose_dgm@yahoo.com.co

Página Web

Centro de investigaciones (CIFAR)

Distribución y canjes

Claudia Álvarez Duquino

calvarez@ucatolica.edu.co
Comité editorial y científico

Cultura y espacio urbano

Carlos Mario Yory, PhD

Universidad Católica de Colombia. Bogotá, Colombia

Sonia Berjman, $\mathrm{PhD}$

ICOMOS-IFLA, Buenos Aires, Argentina

Juan Carlos Pérgolis, MSc Universidad Piloto de Colombia. Bogotá, Colombia

Beatriz García Moreno, PhD

Universidad Nacional de Colombia. Bogotá, Colombia

Proyecto arquitectónico y urbano

Jean-Philippe Garric, PhD, HDR

Université Paris I Panthéon-Sorbonne. Paris, Francia

Debora Domingo Calabuig, PhD

Universidad Politécnica de Valencia, España

Dania González Couret, PhD

Universidad Tecnológica de La Habana, Cuba

Hugo Mondragón López, PhD Pontificia Universidad Católica de Chile. Santiago, Chile

Juan Pablo Duque Cañas, PhD

Universidad Nacional de Colombia. Bogotá, Colombia

Tecnología, medioambiente y sostenibilidad

Mariano Vázquez Espí, PhD

Universidad Politécnica de Madrid, España

Denise Helena Silva Duarte, PhD Universidade de São Paulo (USP), Brasil

Luis Carlos Herrera Sosa, PhD Universidad Autónoma de Ciudad Juárez, México

Claudio Varini, PhD

Universidad Católica de Colombia. Bogotá, Colombia

Luis Gabriel Gómez Azpeitia, PhD Universidad de Colima. Colima, México 


\section{Contenido}

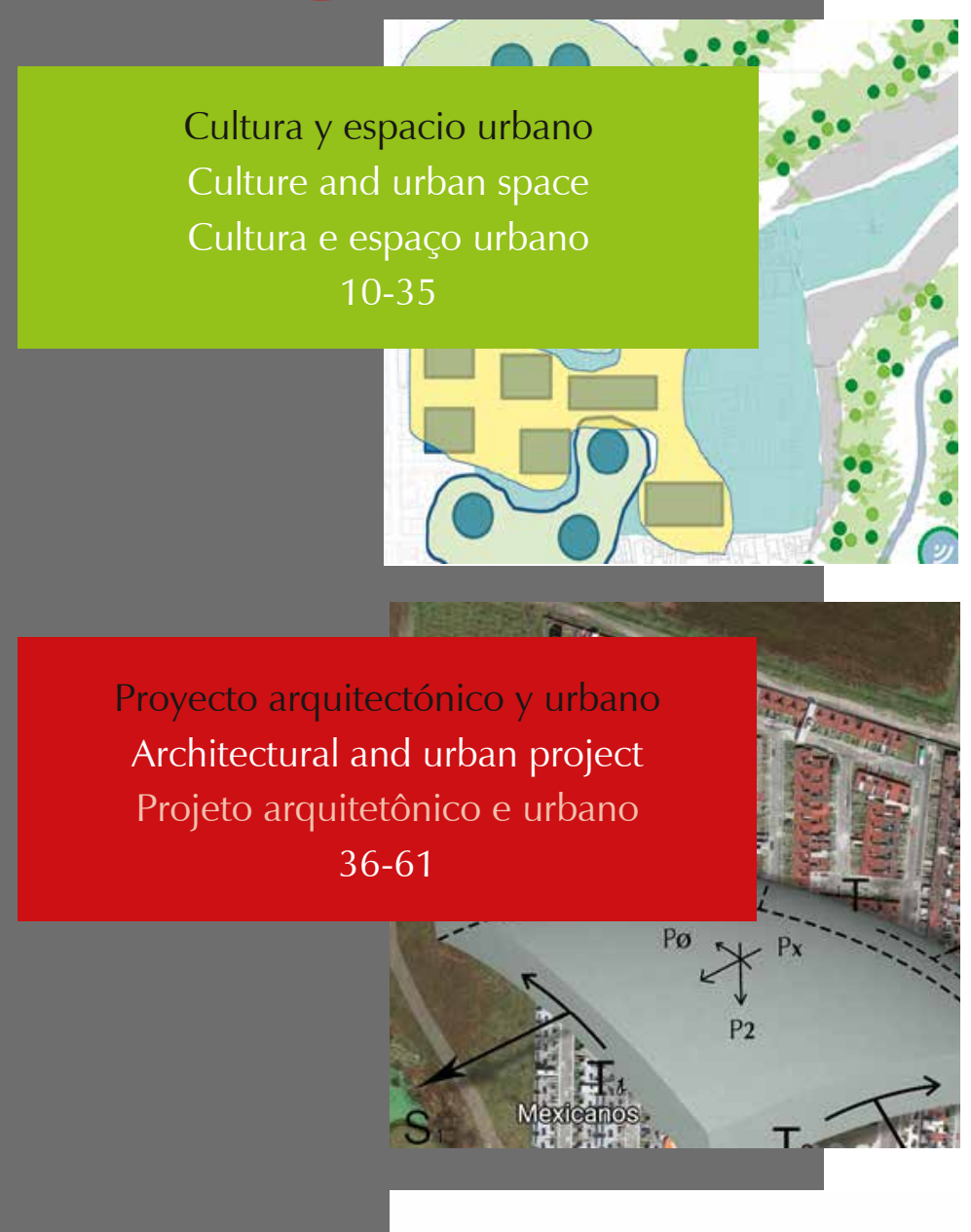

Tecnología, medioambiente

y sostenibilidad

Technology, environment and sustainability

Tecnologia, meio ambiente e sustentabilidade

62-89
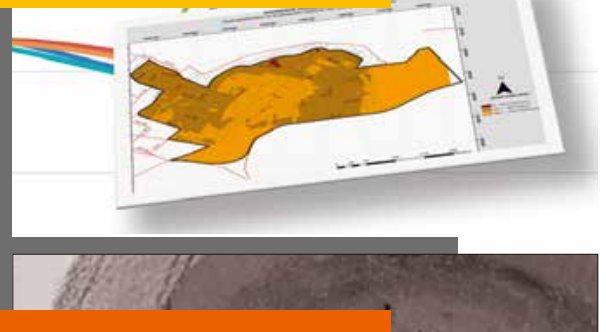

Desde la Facultad

From the Faculty

Da faculdade

90-109
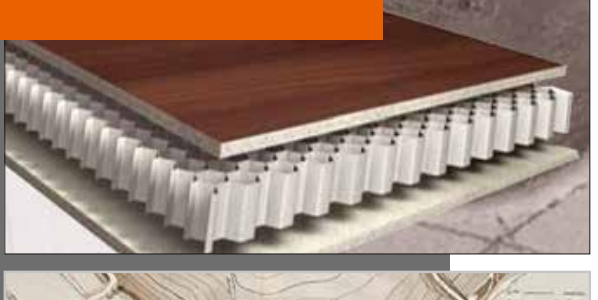

Textos

Texts

Textos

110-126

Los artículos científicos como herramienta de aprendizaje en las escuelas de arquitectura

Carolina Rodríguez-Ahumada

Pág. 3 ES

Paisaje urbano y espacio público como expresión de la vida cotidiana

Morella Briceño-Ávila

Pág. 10

\section{ES EN}

Habitar la quebrada: conformación de gradientes en las trazas vernaculares de los sectores altos de Valparaíso

\section{Omar Eduardo Cañete-Islas}

Juan Luis Moraga-Lacoste

Felipe Mateo López-Flores

Pág. 20

ES

Láminas cilíndricas en la arquitectura colombiana del siglo XX

Jorge Galindo-Díaz

Pág. 36

\section{ES EN}

Retórica simbólica en el espacio arquitectónico

Una mirada antropológica de la casa en la

sobremodernidad

Eska Elena Solano-Meneses

Pág. 51

ES

Ecoenvolventes: análisis del uso de fachadas ventiladas en clima cálido-húmedo

\footnotetext{
Sara Luciani-Mejía

Rodrigo Velasco-Gómez

Roland Hudson
}

Pág. 62

ES

Estrategias metodológicas de análisis urbano frente al cambio climático

Matriz para el diseño adaptativo en asentamientos informales

Adriana Patricia López-Valencia

Oswaldo López-Bernal

Pág. 78

ES

Muro panel térmico estructural compuesto

en guadua y cartón

Modelo experimental aplicado al clima de

la zona cafetera

Renato Cassandro-Cajiao

Pág. 90

\section{ES EN}

Continuidad y transformaciones de modelos

pedagógicos en la École Polytechnique (1867-1910)

Estelle Thibault

Traductores

Andrés Ávila-Gómez

Diana Carolina Ruiz

Pág. 110

ES 
La postulación de un artículo a la Revista de Arquitectura (Bogotá) indica que- el o los autores certifican que conocen y aceptan la política editorial, para lo cual firmarán en original y remitirán el formato RevArq FP00 Carta de originalidad.

La Revista de Arquitectura (Bogotá) maneja una política de Autoarchivo VERDE, según las directrices de SHERPA/RoMEO, por lo cual el autor puede:

- Pre-print del autor: Archivar la versión pre-print (la versión previa a la revisión por pares

- Post-print del autor: Archivar la versión post-print (la versión final posterior a la revisión por pares

- Versión de editor/PDF: Archivar la versión del editor - PDF/HTML/XLM en la maqueta de la Revista de Arquitectura (Bogotá).

El Autoarchivo se debe hacer respetando la licencia de acceso abierto, la integridad y la imagen de la Revista de Arquitectura (Bogotá), también se recomienda incluir la referencia, el vínculo electrónico y el DOI.

El autor o los autores son los titulares del Copyright (c) del texto publicado y la Editorial de la Revista de Arquitectura (Bogotá) solicita la firma de una autorización de reproducción del artículo (RevArq FP03 Autorización reproducción), la cual se acoge a la licencia CC, donde se expresa el derecho de primera publicación de la obra.

La Revista de Arquitectura (Bogotá) se guía por las normas internacionales sobre propiedad intelectual y derechos de autor, y de manera particular el artículo 58 de la Constitución Política de Colombia, la Ley 23 de 1982 y el Acuerdo 172 del 30 de septiembre de 2010 (Reglamento de propiedad intelectual de la Universidad Católica de Colombia)

Para efectos de autoría y coautoría de artículos se diferencian dos tipos: "obra en colaboración" y "obra colectiva". La primera es aquella cuya autoría corresponde a todos los participantes al ser fruto de su trabajo conjunto. En este caso, quien actúa como responsable y persona de contacto debe asegurar que quienes firman como autores han revisado y aprobado la versión final, y dan consentimiento para su divulgación. La obra colectiva es aquella en la que, aunque participan diversos colaboradores, hay un autor que toma la iniciativa la coordinación y realización de dicha obra. En estos casos, la autoría corresponderá a dicha persona (salvo pacto en contrario) y será suficiente únicamente con su autorización de divulgación.

El número de autores por artículo debe estar justificado por el tema, la complejidad y la extensión, y no deberá ser superior a la media de la disciplina, por lo cual se recomienda que no sea mayor de cinco. El orden en que se enuncien corresponderá a los aportes de cada uno a la construcción del texto, se debe evitar la autoría ficticia o regalada. Si se incluyen más personas que trabajaron en la investigación se sugiere que sea en calidad de colaboradores o como parte de los agradecimientos. La Revista de Arquitectura (Bogotá) respetará el número y el orden en que figuren en el original remitido. Si los autores consideran necesario, al final del artículo pueden incluir una breve descripción de los aportes individuales de cada uno de firmantes.

La comunicación se establece con uno de los autores, quien a su vez será el responsable de informar a los demás autores de las notificaciones emitidas por la Revista de Arquitectura (Bogotá).

En virtud de mantener el equilibro de las secciones y las mismas oportunidades para todos los participantes, un mismo autor puede postular dos o más artículos de manera simultánea; si la decisión editorial es favorable y los artículos son aceptados, su publicación se realizará en números diferentes.

\section{A Acceso abierto}

La Revista de Arquitectura (Bogotá), en su misión de divulgar la investigación y apoyar el conocimiento y la discusión en los campos de interés, proporciona acceso abierto, inmediato e irrestricto a su contenido de manera gratuita mediante la distribución de ejemplares impresos y digitales. Los interesados pueden leer, descargar, guardar, copiar y distribuir, imprimir, usar, buscar o referenciar el texto completo o parcial de los artículos o la totalidad de la Revista de Arquitectura (Bogotá).

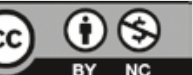

Esta revista se acoge a la licencia Creative Commons (CC BY NC de Atribución - No comercial 4.0 Internacional): "Esta licencia permite a otros entremezclar, ajustar y construir a partir de su obra con fines no comerciales, y aunque en sus nuevas creaciones deban reconocerle su autoría y no puedan ser utilizadas de manera comercial, no tienen que estar bajo una licencia con los mismos términos".

La Revista de Arquitectura es divulgada en centros y grupos de investigación, en bibliotecas y universidades, y en las principales facultades de Arquitectura mediante acceso abierto a la versión digital y suscripción anual al ejemplar impreso o por medio de canje, este último se formaliza mediante el formato RevArq FP20 Canjes

Para aumentar su visibilidad y el impacto de los artículos, se envían a bases de datos y sistemas de indexación y resumen (SIR) y, asimismo, pueden ser consultados y descargados en la página web de la revista.

La Revista de Arquitectura no maneja cobros, tarifas o tasas de publicación de artículo (Article Processing Charge-APC), o por el sometimiento de textos a la publicación.

\section{(1)Ética y buenas prácticas}

La Revista de Arquitectura se compromete a cumplir y respetar las normas éticas en todas las etapas del proceso de publicación. Los autores de los artículos publicados darán cumplimiento a los principios éticos contenidos en las diferentes declaraciones y legislaciones sobre propiedad intelectual y derechos de autor específicos del país donde se realizó la investigación. En consecuencia, los autores de los artículos postulados y aceptados para publicar, que presentan resultados de investigación, deben firmar la declaración de originalidad (formato RevArq FP00 Carta de originalidad).

La Revista de Arquitectura reconoce y adopta los principios de transparencia y buenas prácticas descritos por COPE, "Principles of Transparency and Best Practice in Scholarly Publishing" (2015).

El equipo editorial tiene la obligación de guardar la confidencialidad acerca de los artículos recibidos, y abstenerse de usar en sus propias investigaciones datos, argumentos o interpretaciones hasta tanto el artículo no sea publicado. También debe ser imparcial y gestionar los artículos de manera adecuada y en los plazos establecidos. La selección de revisores se hará con objetividad y estos deberán responder a la temática del artículo.

El editor, los autores y los revisores deben seguir las normas éticas internacionales definidas por el Committee on Publication Ethics (COPE), con el fin de evitar casos de:

- Fabricación, falsificación u omisión de datos.

- Plagio y autoplagio.

- Publicación redundante, duplicada o fragmentada.

- Omisión de referencias a las fuentes consultadas.

- Utilización de contenidos sin permiso o sin justificación.

- Apropiación individual de autoría colectiva.

- Cambios de autoría.

- Conflicto de interés (CDI) no revelado o declarado.

- Otras que pudieran surgir en el proceso de investigación y publicación. La fabricación de resultados se genera al mostrar datos inventados por los autores; la falsificación resulta cuando los datos son manipulados y cambiados a capricho de los autores; la omisión se origina cuando los autores ocultan deliberadamente un hecho o dato. El plagio se da cuando un autor presenta como ideas propias datos creados por otros. Los casos de plagio son los siguientes: copia directa de un texto sin entrecomillar o citar la fuente, modificación de algunas palabras del texto, paráfrasis y falta de agradecimientos; el autoplagio se da cuando el mismo autor reutiliza material propio que ya fue publicado, pero sin indicar la referencia al trabajo anterior. La revista se apoya en herramientas digitales que detectan cualquiera de estos casos en los artículos postulados, y es labor de los editores y revisores velar por la originalidad y fidelidad en la citación. La publicación redundante o duplicada se refiere a la copia total, parcial o alterada de un trabajo ya publicado por el mismo autor

En caso de sospechar de alguna mala conducta se recomienda seguir los diagramas de flujo elaborados por COPE (2008), con el fin de determinar las acciones correspondientes.

La Revista de Arquitectura se reserva el derecho de retractación de publicación de aquellos artículos que, posterior a su publicación, se demuestre que presentan errores de buena fe, o cometieron fraudes o malas prácticas científicas. Esta decisión se apoyará en "Retraction Guidelines" (COPE, 2009). Si el error es menor, este se podrá rectificar mediante una nota editorial de corrección o una fe de erratas. Los autores también tienen la posibilidad de solicitar la retractación de publicación cuando descubran que su trabajo presenta errores graves. En todos los casos se conservará la versión electrónica y se harán las advertencias de forma clara e inequívoca.

\section{A Privacidad y manejo de la información.} Habeas Data

Para dar cumplimiento a lo previsto en el artículo 10 del Decreto 1377 de 2013, reglamentario de la Ley 1581 de 2012, y según el Acuerdo 002 del 4 de septiembre de 2013 de la Universidad Católica de Colombia, "por el cual se aprueba el manual de políticas de tratamiento de datos personales":

La Universidad Católica de Colombia, considerada como responsable o encargada del tratamiento de datos personales, manifiesta que los datos personales de los autores, integrantes de los comités y pares revisores, se encuentran incluidos en nuestras bases de datos; por lo anterior, y en cumplimiento de las disposiciones legales vigentes, la Universidad solicitará siempre su autorización, para que en desarrollo de sus funciones propias como Institución de Educación Superior, en especial las relacionadas con la docencia, la extensión y la investigación, la Universidad Católica de Colombia pueda recolectar, recaudar, almacenar, usar, circular, suprimir, procesar, intercambiar, compilar, dar tratamiento, actualizar, transmitir o transferir a terceros países y disponer de los datos que le han suministrado y que han sido incorporados en las bases de datos de todo tipo que reposan en la Universidad.

La Universidad Católica de Colombia queda autorizada, de manera expresa e inequívoca, en los términos señalados por el Decreto 1377 de 2013, para mantener y manejar la información de nuestros colaboradores (autores, integrantes de los diferentes comités y pares revisores); así mismo, los colaboradores podrán ejercer sus derechos a conocer, actualizar, rectificar y suprimir sus datos personales, para lo cual se han dispuesto las siguientes cuentas de correo electrónico: 
La Revista de Arquitectura (Bogotá) recibe artículos de manera permanente. Los artículos se procesan a medida que se postulan, dependiendo el flujo editorial de cada sección.

El idioma principal es el español, y como opcionales están definidos el inglés, el portugués y el francés; los textos pueden ser escritos y presentados en cualquiera de estos.

Los artículos postulados deben corresponder a las categorías universalmente aceptadas como producto de investigación, ser originales e inéditos y sus contenidos responder a criterios de precisión, claridad y brevedad.

Como punto de referencia se pueden tomar las tipologías y definiciones del Índice Bibliográfico Nacional, Publindex (2010) que se describen la continuación:

1. Artículo de revisión: documento resultado de una investigación terminada donde se analizan, sistematizan e integran los resultados de investigaciones publicadas o no publicadas, sobre un campo en ciencia o tecnología, con el fin de dar cuenta de los avances y las tendencias de desarrollo. Se caracteriza por presentar una cuidadosa revisión bibliográfica de por lo menos 50 referencias.
2. Artículo de investigación científica y tecnológica: documento que presenta, de manera detallada, los resultados originales de proyectos terminados de investigación. La estructura generalmente utilizada contiene cuatro apartes importantes: introducción, metodología, resultados y conclusiones.

3. Artículo de reflexión: documento que presenta resultados de investigación terminada desde una perspectiva analítica, interpretativa o crítica del autor, sobre un tema específico, recurriendo a fuentes originales.

Adicional a estas tipologías, se pueden presentar otro tipo de artículos asociados a procesos de investigación-creación y/o investigación proyectual. En todos los casos se debe presentar la información suficiente para que cualquier investigador pueda reproducir la investigación y confirmar o refutar las interpretaciones defendidas y sea evidente el aporte a la disciplina.

En todos los casos se debe presentar la información suficiente para que cualquier investigador pueda reproducir la investigación y confirmar o refutar las interpretaciones defendidas.

\section{(A) Instrucciones para postular artículos}

Postular el artículo en la página web de la Revista de Arquitectura (Bogotá) y adjuntar comunicación escrita dirigida al editor RevArq_FP00 Carta de originalidad (debidamente firmada por todos los autores en original); de igual manera, se debe diligenciar el formato de hoja de vida RevArq FP01 Hoja de Vida (una por cada autor).

En la comunicación escrita el autor expresa que conoce y acepta la política editorial de la Revista de Arquitectura (Bogotá), que el artículo no está postulado para publicación simultáneamente en otras revistas u órganos editoriales y que no existe conflicto de intereses (ver modelo RevArq FP06 CDI) y que, de ser aceptado, concederá permiso de primera publicación, no exclusiva a nombre de la Universidad Católica de Colombia como editora de la revista.

Los artículos deben tener en cuenta las siguientes recomendaciones:

- En la primera página del documento se debe incluir:

Tírulo: no exceder 15 palabras

Subtítulo: opcional, complementa el título o indica las principales subdivisiones del texto.

Nombre del autor o autores: nombres y apellidos completos o según modelo de citación adoptado por el autor para la normalización de los nombres del investigador. Como nota al pie (máximo 150 palabras): formación académica, experiencia profesional e investigativa, vinculación laboral, código https://orcid.org/, premios o reconocimientos, publicaciones representativas e información de contacto, correo electrónico.

Filiación institucional: debajo del nombre se debe declarar la ins-titución en la cual se desarrolló el producto, de la cual recibió apoyo o aquella que respalda el trabajo investigativo.

Resumen: debe ser analítico, se redacta en un solo párrafo, da cuenta del tema, el objetivo, la metodología, los resultados y las conclusiones; no debe exceder las 150 palabras.

Palabras clave: cinco palabras o grupo de palabras, ordenadas alfabéticamente y que no se encuentren en el título o subtítulo; estas sirven para clasificar temáticamente al artículo. Se recomienda emplear principalmente palabras definidas en el tesauro de la Unesco (http://databases. unesco.org/thessp/), en el tesauro de Arte \& Arquitectura (C) (www.aatespanol.cl), o Vitruvio (http://vocabularyserver.com/vitruvio/)

También se recomienda incluir título, resumen y palabras clave en segundo idioma.

- La segunda página y siguientes deben tener en cuenta:

El cuerpo del artículo se divide en: Introducción, Metodología, Resultados y Discusión de resultados; posteriormente se presentan las Conclusiones, y luego las Referencias bibliográficas y los Anexos (método IMRYD). Las tablas y figuras se deben incorporar en el texto.

Descripción del proyecto de investigación: en la introducción se debe describir el tipo de artículo y brevemente el marco investigativo del cual es resultado y diligenciar el formato (RevArq FP02 Info Proyectos de Investigación).

TEXTO: todas las páginas deben venir numeradas y con el título de artículo en la parte superior de la página. Márgenes de $3 \mathrm{~cm}$ por todos los lados, interlineado doble, fuente Arial o Times New Roman de 12 puntos, texto justificado (Ver plantilla para presentación de artículos). La extensión de los artículos debe ser de alrededor de 5.000 palabras ( \pm 20 páginas, incluyendo gráficos, tablas, referencias, etc.); como mínimo 3.500 y máximo 8.000 palabras. Se debe seguir el estilo vigente y recomendado en el Manual para Publicación de la American Psychological Association (APA). (Para mayor información véase http://www.apastyle.org/)
Citas y notas al pie: las notas aclaratorias o notas al pie no deben exceder cinco líneas o 40 palabras, de lo contrario estas deben ser incorporadas al texto general. Las citas pueden ser:

Corta: (con menos de 40 palabras) se incorporan al texto y pueden ser: textuales (se encierran entre dobles comillas), parafraseo o resumen (se escriben en palabras del autor dentro del texto).

Cita textual extensa: (mayor de 40 palabras) debe ser dispuesta en un renglón y un bloque independiente con sangrías y omitiendo las comillas, no olvidar en ningún caso la referencia del autor (Apellido, año, página).

Referencias: como modelo para la construcción de referencias se emplea el estilo recomendado en el Manual para Publicación de la American Psychological Association (APA) (http://www.apastyle.org/).

Siglas: en caso de emplear siglas en el texto, las figuras o las tablas, se debe proporcionar la equivalencia completa la primera vez que se empleen y encerrarlas entre paréntesis. En el caso de citar personajes reconocidos se deben colocar nombres o apellidos completos, nunca emplear abreviaturas.

Figuras y tablas: las figuras (gráficos, diagramas, ilustraciones, planos, mapas o fotografías) y las tablas deben ir numeradas y contener título o leyenda explicativa relacionada con el tema del artículo, que no exceda las 15 palabras (Figura 1. xxxxx, Tabla 1. xxxx, etc.) y la procedencia (fuente: autor o fuente, año, página). Estas se deben referenciar en el texto de forma directa o entre paréntesis; se recomienda hacerlo con referencias cruzadas.

También se deben entregar en medio digital, independiente del texto, en formatos editables o abiertos. La marcación de los archivos debe corresponder a la incluida en el texto. Según la extensión del artículo se deben incluir de 5 a 10 gráficos. Ver guía para la búsqueda de imágenes de dominio público o bajo licencias Creative Commons (CC).

El autor es el responsable de adquirir los derechos o las autorizaciones de reproducción a que haya lugar para imágenes o gráficos tomados de otras fuentes, así como de entrevistas o material generado po colaboradores diferentes a los autores; de igual manera, se debe garantizar la protección de datos e identidades para los casos que sea necesario.

Fotografía: pueden ser entregadas en original para ser digitalizadas, de lo contrario se deben digitalizar con una resolución igual o superior a 300 dpi para imágenes a color y 600 para escala de grises. Los formatos de las imágenes pueden ser TIFF, PSD o JPG, y deben cumplir con las características expresadas en el punto anterior (figuras).

Planimetría: se debe entregar la planimetría original en medio digital, en lo posible en formato CAD, y sus respectivos archivos de plumas o en PDF; de no ser posible, se deben hacer impresiones en tamaño carta con las referencias de los espacios mediante numeración y lista adjunta. Deben tener escala gráfica, escala numérica, norte, coordenadas y localización. En lo posible, no deben contener textos, achurados o tramas.

Para más detalles, consultar el documento RevArq Parámetros para Autores Descripción en el portal web de la Revista de Arquitectura (Bogotá)

\section{Beneficios}

Como reconocimiento a los autores, se les hará envío postal de dos ejemplares de la edición impresa sin ningún costo y entregada en la dirección consignada en el formato de hoja de vida (RevArq FP01); adicionalmente, se enviará el vínculo para la descarga de la versión digital.

También se enviará una constancia informativa en la que se relaciona a publicación del artículo y, de manera opcional, se pueden detallar las fechas del proceso editorial y el arbitraje realizado. 
La selección de revisores se realiza de acuerdo con los siguientes criterios:

- Afinidad temática.

- Formación académica.

- Experiencia investigativa y profesional.

- Producción editorial en revistas similares o en libros resultado de investigación.

El proceso de arbitraje se basa en los principios de equidad e imparcialidad, y en los criterios de calidad y pertinencia.

El desarrollo de la revisión se realiza según el formato (RevArq FP10 Evaluación de artículos) y las observaciones que el revisor considere necesarias en el cuerpo del artículo. En cualquiera de los conceptos que emita el revisor (Aceptar, Publicable con modificaciones, Reevaluable o No publicable), y como parte de la labor formativa y de comunidad académica, el revisor hará sugerencias para mejorar el documento. El revisor podrá solicitar una nueva relectura del artículo después de los ajustes realizados por el autor.

El revisor también deberá diligenciar el formato RevArq FP01 Hoja de Vida, con el fin de certificar y soportar el proceso de revisión ante los SIR que así lo soliciten.

En el proceso de arbitraje se emplea el método doble ciego, los nombres del revisor no serán conocidos por el autor y viceversa. Con el fin de garantizar el anonimato del autor, al artículo postulado se le han podido suprimir nombres, instituciones o imágenes que puedan ser asociadas de manera directa al autor.

Aunque se procura el anonimato, una vez recibida la invitación como par revisor del artículo, el revisor debe cerciorarse de que no exista conflicto de intereses (CDI) o alguna limitante que afecte la revisión o que pueda ser vista como tal (lazos familiares, amistad o enemistad, vínculos contractuales o laborales, posiciones éticas, etc.), de presentarse esta situación se notificara al editor. (Ver modelo RevArq FP06 CDI).

Dada la confidencialidad del proceso de revisión, y considerando los derechos de autor y de propiedad intelectual que pueda haber sobre el material que se entrega, el revisor se compromete a mantener en absoluta reserva su labor, a limitar el uso de la obra entregada solo para el propósito designado y a devolver la documentación remitida una vez concluya la actividad.

El tiempo establecido para las revisiones de pares es de máximo un mes a partir de la confirmación de la recepción de la documentación. Ese plazo podrá ser modificado de mutuo acuerdo entre el editor y el revisor, siempre y cuando no afecte la periodicidad de la revista, la impresión o el tiempo para emitir una respuesta al autor.

Los revisores se acogerán a "COPE Ethical Guidelines for Peer Reviewers" de COPE.

\section{Beneficios}

Como retribución a los revisores se les hará envío postal de un ejemplar de la edición impresa sin ningún costo y entregada en la dirección consignada en el formato de hoja de vida. También, si es de interés para el revisor, podrá hacer la solicitud de alguna de las publicaciones editadas y presentes en el catálogo de publicaciones de la UNIVERSIDAD CATÓLICA DE COLOMBIA, previa aprobación de la Editorial y sujeto a la disponibilidad.

Si lo desea tendrá derecho a una constancia de la colaboración en la revisión de artículos, la cual solo contendrá el periodo en el cua se realizó la actividad. También tendrá la posibilidad de aceptar o no la publicación de su nombre, nacionalidad y nivel máximo de formación en la página web de la Revista de Arquitectura (Bogotá) en su calidad de colaborador.

\section{A Proceso de revisión por pares}

Luego de la postulación del artículo, el editor de la Revista de Arquitectura (Bogotá) selecciona y clasifica los artículos que cumplen con los requisitos establecidos en las directrices para los autores. El editor podrá rechazar en primera instancia artículos, sin recurrir a un proceso de revisión, si los considera de baja calidad o por presentar evidencias de faltas éticas o documentación incompleta.

Los artículos se someterán a un primer dictamen del editor, de los editores de sección y del Comité Editorial, teniendo en cuenta:

- Afinidad temática, relevancia del tema y correspondencia con las secciones definidas.

- Respaldo investigativo.

- Coherencia en el desarrollo del artículo, así como una correcta redacción y ortografía.
- Relación entre las figuras y tablas con el texto del artículo.

En esta revisión se verificará el nivel de originalidad mediante el uso de software especializado (Ithenticate o similar) y recursos digitales existentes para tal fin, también se observará la coherencia y claridad en los apartados del documento (modelo IMRYD) la calidad de las fuentes y la adecuada citación, esto quedará consignado en el formato (RevArq FP09 Revisión de artículos); esta información será cargada a la plataforma de gestión editorial y estará a disposición del autor.

En caso de que el artículo requiera ajustes preliminares, será devuelto al autor antes de ser remitido a revisores. En este caso, el autor tendrá veinte días para remitir nuevamente el texto con los ajustes solicitados.

Después de la preselección se asignan mínimo dos revisores especializados, quienes emitirán su concepto utilizando el formato (RevArq FP10 Evaluación de artículos) y las anotaciones que consideren oportunas en el texto; en esta etapa se garantizará la confidencialidad y el anonimato de autores y revisores (modalidad doble ciego)

Del proceso de revisión se emite uno de los siguientes conceptos que será reportado al autor:

- Aceptar el envío: con o sin observaciones.

- Publicable con modificaciones: se podrá sugerir la forma más adecuada para una nueva presentación, el autor puede o no aceptar las observaciones según sus argumentos. Si las acepta, cuenta con quince días para realizar los ajustes pertinentes.

- Reevaluable: cumple con algunos criterios y debe ser corregido. Es necesario hacer modificaciones puntuales y estructurales al artículo. En este caso, el revisor puede aceptar o rechazar hacer una nueva lectura del artículo luego de ajustado.

- No publicable: el autor puede volver a postular el artículo e iniciar nuevamente el proceso de arbitraje, siempre y cuando se evidencien los ajustes correspondientes.

En el caso de presentarse diferencias sustanciales y contradictorias en los conceptos sobre la recomendación del revisor, el editor remitirá el artículo a un revisor más o a un miembro del Comité Editorial quien podrá actuar como tercer árbitro, con el fin de tomar una decisión editorial sobre la publicación de artículo.

Los autores deberán considerar las observaciones de los revisores o de los editores, y cada corrección incorporada u omitida debe quedar justificada en el texto o en una comunicación adjunta. En el caso que los autores omitan las indicaciones realizadas sin una argumentación adecuada, el artículo será devuelto y no se dará por recibido hasta que no exista claridad al respecto. El editor respetará la independencia intelectual de los autores y a estos se les brindará el derecho de réplica en caso de que los artículos hayan sido evaluados negativamente y rechazados. Los autores, con su usuario y contraseña, podrán ingresar a la plataforma de Gestión Editorial, donde encontrarán los conceptos emitidos y la decisición sobre el artículo.

El editor y el Comité Editorial se reservan el derecho de aceptar o no la publicación del material recibido. También se reservan el derecho de sugerir modificaciones de forma, ajustar las palabras clave o el resumen y de realizar la corrección de estilo. El autor conocerá la versión final del texto antes de la publicación oficial del mismo.

Cuando un artículo es aceptado para su publicación, el autor debe firmar la autorización de reproducción (RevArq FP03 Autorización reproducción). Para más información ver: Política de derechos de autor

\section{Notas aclaratorias:}

La Revista de Arquitectura (Bogotá) busca el equilibrio entre las secciones, motivo por el cual, aunque un artículo sea aceptado o continúe en proceso de revisión, podrá quedar aplazado para ser publicado en un próximo número; en este caso, el autor estará en la posibilidad de retirar la postulación del artículo o de incluirlo en el banco de artículos del próximo número.

El editor y los editores de sección de la Revista de Arquitectura (Bogotá) son los encargados de establecer contacto entre los autores y revisores, ya que estos procesos se realizan de manera anónima.
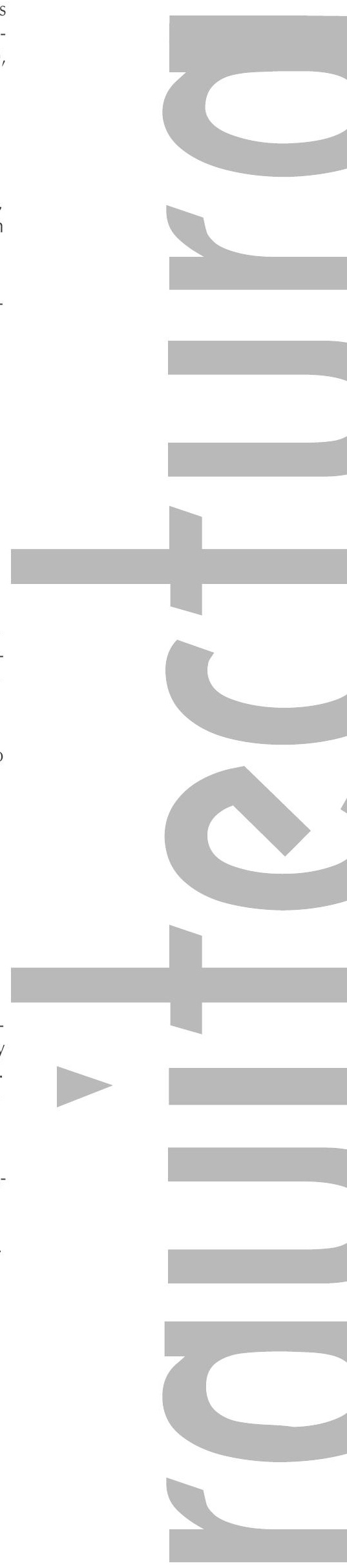

\section{.}

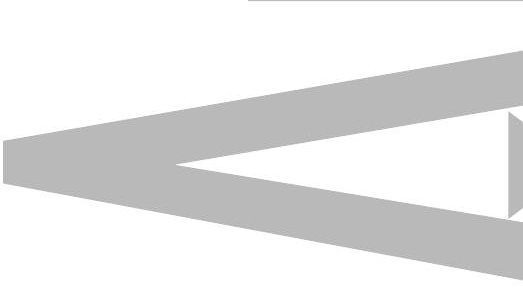


Los artículos científicos como herramienta de aprendizaje en las escuelas de arquitectura

نं Scientific articles as a learning tool in architecture schools

$\ll \quad$ Os artigos científicos como ferramenta de aprendizagem

nas escolas de arquitetura

Carolina Rodriguez-Ahumada

Paisaje urbano y espacio público como expresión 으 de la vida cotidiana

Urban landscape and public space as an expression of everyday life

نั Paisagem urbana e espaço público como expressão da vida cotidiana

Habitar la quebrada: conformación de gradientes en las trazas 을 vernaculares de los sectores altos de Valparaíso

Inhabiting the ravine: Gradient configuration in the vernacular layouts of the

¿ higher sectors of Valparaíso

Habitar a quebrada: conformação de níveis nos traçados vernaculares dos setores altos de Valparaíso

\section{Omar Eduardo Canete-Islas}

Juan Luis Moraga-Lacoste

Felipe Mateo López-Flores

Láminas cilíndricas en la arquitectura colombiana del siglo $X X$ Cylindrical shells in Colombian architecture in the 20th century

Estruturas laminares cilíndricas na arquitetura colombiana do século $X X$ 这 Jorge Galindo-Díaz

Retórica simbólica en el espacio arquitectónico. Una mirada antropológica de la casa en la sobremodernidad

in Symbolic Rhetoric in the Architectural Space: An Anthropological View of the

ن House in the Age of Supermodernity

Retórica simbólica no espaço arquitetônico. Um olhar antropológico da casa na sobremodernidade

\section{Eska Elena Solano-Meneses}

Ecoenvolventes: análisis del uso de fachadas ventiladas en clima ㅈ cálido-húmedo

نं Eco-friendly coverings: Analysis of the use of ventilated facades in hot, humid

ن⿺ weather

Ecoenvolventes: análise do uso de fachadas ventiladas em clima quente úmido

Sara Luciani-Meía

Rodrigo Velasco-Gómez

Roland Hudson

Estrategias metodológicas de análisis urbano frente al cambio œ climático. Matriz para el diseño adaptativo en asentamientos $\stackrel{\infty}{\text { informales }}$

Methodological strategies for urban analysis in the face of climate change. An adaptive design matrix for informal settlements

Estratégias metodológicas de análise urbana ante mudanças climáticas. Matriz para o desenho adaptativo em assentamentos informais

Adriana Patricia López-Valencia

Muro panel térmico estructural compuesto en guadua y - cartónModelo experimental aplicado al clima de la zona cafetera

․ Structural thermal panel wall composed of bamboo and cardboard.

Experimental model applied to the climate of the Coffee Region

$\ltimes$ Muro painel térmico estrutural composto de bambu e papelão. Modelo experimental aplicado ao clima da zona cafeeira

\section{Renato Cassandro-Cajiao}

Continuidad y transformaciones de modelos pedagógicos en la École Polytechnique (1867-1910)

으 Continuity and transformations of teaching models at the École Polytechnique

二 (1867-1910)

ن Continuidade e transformações de modelos pedagógicos na École

¿ Polytechnique (I867-1910) 